\title{
Mechanisms for pituitary tumorigenesis: the plastic pituitary
}

\author{
Shlomo Melmed \\ Cedars-Sinai Medical Center, David Geffen School of Medicine at the University of California, Los Angeles, Los Angeles, \\ California, USA
}

\begin{abstract}
The anterior pituitary gland integrates the repertoire of hormonal signals controlling thyroid, adrenal, reproductive, and growth functions. The gland responds to complex central and peripheral signals by trophic hormone secretion and by undergoing reversible plastic changes in cell growth leading to hyperplasia, involution, or benign adenomas arising from functional pituitary cells. Discussed herein are the mechanisms underlying hereditary pituitary hypoplasia, reversible pituitary hyperplasia, excess hormone production, and tumor initiation and promotion associated with normal and abnormal pituitary differentiation in health and disease.
\end{abstract}

J. Clin. Invest. 112:1603-1618 (2003). doi:10.1172/JCI200320401.

\section{Introduction}

The pituitary gland responds to complex central and peripheral signals by two mechanisms. First, trophic hormone secretion is exquisitely controlled to regulate homeostasis. Second, developmental or acquired pituitary signals may elicit plastic pituitary growth responses, consisting of either hypoplasia, hyperplasia, or adenoma formation. These clinically apparent plastic changes of pituitary mass are indicative of physiologic or pathologic responses to extrapituitary or intrapituitary signals. Pituitary proliferative changes are usually accompanied by functional disorders of hormone secretion, leading to syndromes of hormone deficiency or excess. Mutations of early developmental genes (including $R p x, L h x 3, L h x 4$, and Pitx2) pleiotropically affect adjacent midline structures, resulting in pituitary hypoplasia and pituitary hormone deficits, while muta-

The Science in Medicine series is supported in part by a generous grant from the Doris Duke Charitable Foundation.

Address correspondence to: Shlomo Melmed, Cedars-Sinai Medical Center, 8700 Beverly Boulevard, Room 2015,

Los Angeles, California 90048, USA. Phone: (310) 423-4691; Fax: (310) 423-0119; E-mail: melmed@csmc.edu.

Conflict of interest: The author has declared that no conflict of interest exists.

Nonstandard abbreviations used: $G$ protein-coupled receptor (GPCR); growth hormone (GH); luteinizing hormone (LH); follicle-stimulating hormone (FSH); prolactin (PRL); thyroidstimulating hormone (TSH); adrenocorticotropic hormone (ACTH); GH-releasing hormone (GHRH); nerve growth factor (NGF); proopiomelanocortin (POMC); cyclin-dependent kinase (CDK); estrogen receptor (ER); pituitary tumor transforming gene (PTTG); corticotropin-releasing hormone (CRH); dopamine D2 receptor (DRD2); somatostatin receptor subtype (SSTR); cAMP response element-binding protein (CREB); Carney complex (CNC); protein kinase A (PKA); PKA type I- $\alpha$ regulatory subunit (PRKAR1 $\alpha$ ); multiple endocrine neoplasia type I (MEN I); loss of heterozygosity (LOH). tions in genes determining specific pituitary lineages (including Prop1, Pit1, and Tpit) are involved in pituitary hormone deficiencies with hypoplasia. Excess pituitary hormone secretion is usually associated with invariably benign monoclonal adenomas arising from a specific cell type, and although pituitary chromosome instability is an early hallmark of pituitary adenoma development and growth, pituitary carcinoma is very rare, further supporting the concept that pituitary adenomas have the capacity for reversible plasticity.

The hypothalamic-anterior pituitary unit integrates stimulatory and inhibitory central and peripheral signals to synthesize and secrete hormones by five highly differentiated cell types: somatotrophs, gonadotrophs, lactotrophs, thyrotrophs, and corticotrophs (Figure 1). Each of these cell types expresses unique $G$ protein-coupled receptors (GPCRs), which are specific for hypothalamic releasing and inhibiting hormones. These peptides traverse the hypophyseal portal system and impinge upon their cognate pituicytes to regulate the synthesis and secretion of anterior pituitary trophic hormones that regulate growth (including growth hormone $[\mathrm{GH}]$ ), sexual development and function (including luteinizing hormone $[\mathrm{LH}]$ and follicle-stimulating hormone $[\mathrm{FSH}]$ ), lactation (including prolactin [PRL]), metabolism (including thyroid-stimulating hormone $[\mathrm{TSH}]$ ), and stress responses (including adrenocorticotropic hormone $[\mathrm{ACTH}]$ ). The gland itself responds to central and peripheral signals by undergoing reversible changes in cell growth leading to hyperplasia, involution or true adenoma formation. Using doublelabeling with both BrdU and specific anterior pituitary hormone markers, it is apparent that even after their differentiation, pituitary cells continue mitosis, which may be augmented under certain conditions in the adult (e.g., pregnancy). About $30 \%$ of rat pituitary cells 


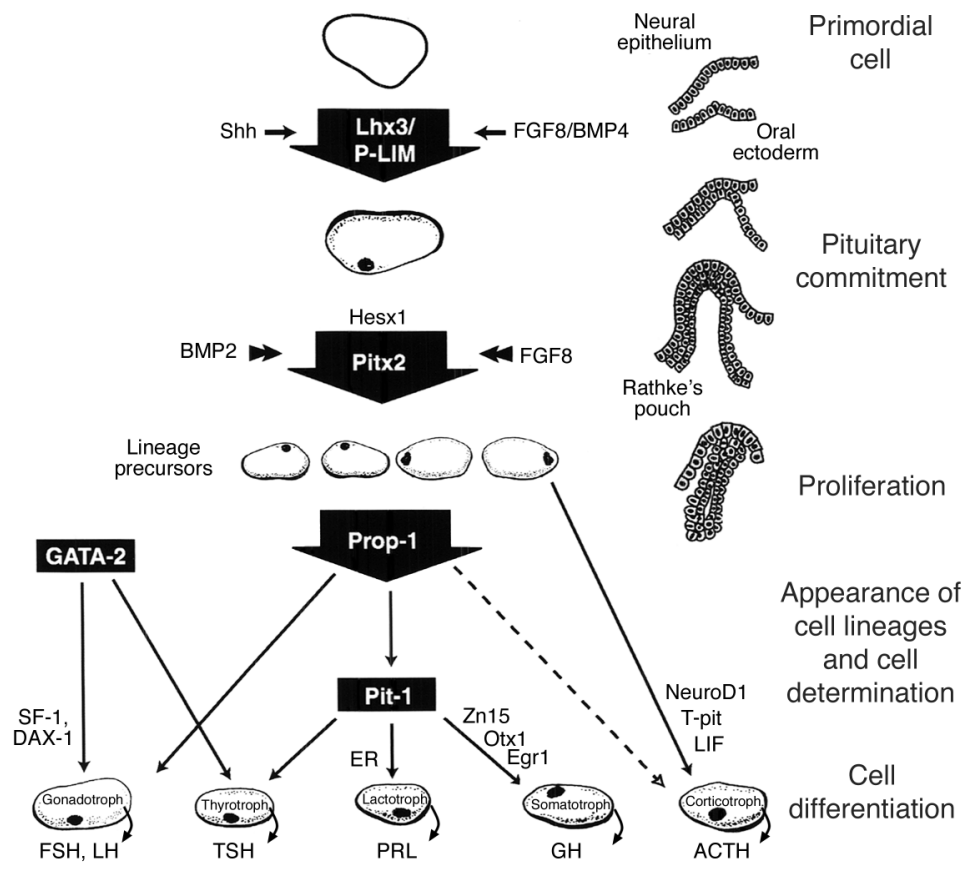

Figure 1

Model for development of human anterior pituitary cell lineage determination by a temporally controlled cascade of transcription factors. Trophic cells are depicted with transcription factors known to determine cell-specific human or murine gene expression. Adapted with permission from W.B. Saunders (139), Humana Press (140), and Karger Publishing (141).

arise from "self-mitosis" of already differentiated cells, while others are produced by differentiation of hitherto undifferentiated cells, or possibly from pituitary stem cells. Thus, proliferative and apoptotic changes in the pituitary are observed during the first year of rodent life (1), and likely also occur in the human pituitary (2).

Tumors may arise from any of these cells, and their secretory products depend upon the cell of origin. Functional classification of pituitary tumors is facilitated by immunocytochemical or in situ mRNA detection of cell gene products, as well as by measurement of circulating trophic and target hormone concentrations (Figure 2). ACTH oversecretion results in Cushing disease, with features of hypercortisolism; GH hypersecretion leads to acral overgrowth and metabolic dysfunction associated with acromegaly; and PRL hypersecretion leads to gonadal failure, secondary infertility, and galactorrhea. More rarely, TSH hypersecretion leads to hyperthyroxinemia and goiter, and hypersecreted gonadotropins (or their respective subunits) lead to gonadal dysfunction. Mixed tumors cosecreting GH with PRL, TSH, or ACTH may also arise from single cells. In contrast, tumors arising from gonadotroph cells do not efficiently secrete their gene products, and they are usually clinically silent (3-5).

Hormone secretion from pituitary tumors, although excessive and associated with unique phenotypic features, often retains intact trophic control. For example, dopaminergic agents appropriately suppress PRL secre- tion by prolactinomas, and dexamethasone may suppress ACTH secretion in patients with pituitary Cushing disease. Excessive secretory patterns are also not uniform, and may in fact cycle between normal and excessive hormone release.

Several characteristic hallmarks of pituitary neoplasia point to a unique growth behavior distinct from that of other endocrine and nonendocrine malignancies. Pituitary tumors are invariably benign, and although aggressive local growth may occur, their general failure to proceed to true malignancy with demonstrable extracranial metastases is intriguing. These adenomas grow slowly, and are discovered in up to $25 \%$ of unselected autopsy specimens. Although the natural history of pituitary microadenoma growth is difficult to ascertain because of the intrinsic inaccessibility of pituitary tissue for study, it is clear that microadenomas do not invariably progress to macroadenomas; furthermore, macroadenomas are stable or exhibit very slow growth, and may in fact resolve spontaneously (6). Oncogene mutations commonly encountered in nonendocrine neoplasms (e.g., ras and p53) are not generally present in pituitary adenomas, yet disturbed intrapituitary paracrine growth factor expression and action have been extensively documented (3-5). Study of human pituitary tissue is challenging due to several limitations, including the anatomic inaccessibility of the pituitary gland, the lack of functional human cell lines in culture, the paucity of faithful animal models, and unique differentiated tumor behaviors. Although mouse models may differ from human counterparts, their study provides important insights into human pituitary tumor pathogenesis. Animal studies of pituitary proliferative changes have largely followed two approaches. First, disruption of known tumor suppressor genes tested in transgenic animal models has revealed unexpected pituitary hyperplasia and tumor phenotypes (e.g., Rb and p27). Second, transgenic animals have been used to test genes known for their pituitary-regulatory functions (e.g., GH-releasing hormone [GHRH], nerve growth factor [NGF], and cytokines). These lines of investigation have also made it possible to understand the role of pituitary cell cycle proteins (Table 1).

In light of these observations, the approach to understanding pituitary adenoma pathogenesis requires insights into factors regulating pituitary growth, from hypoplasia through hyperplasia, and ultimately true adenoma development (Table 2).

Pituitary hypoplasia: transcription factor regulation of pituitary development. Hormone-specific anterior pituicytes are embryologically derived from a pluripotent precursor, and arise as a consequence of concerted tem- 


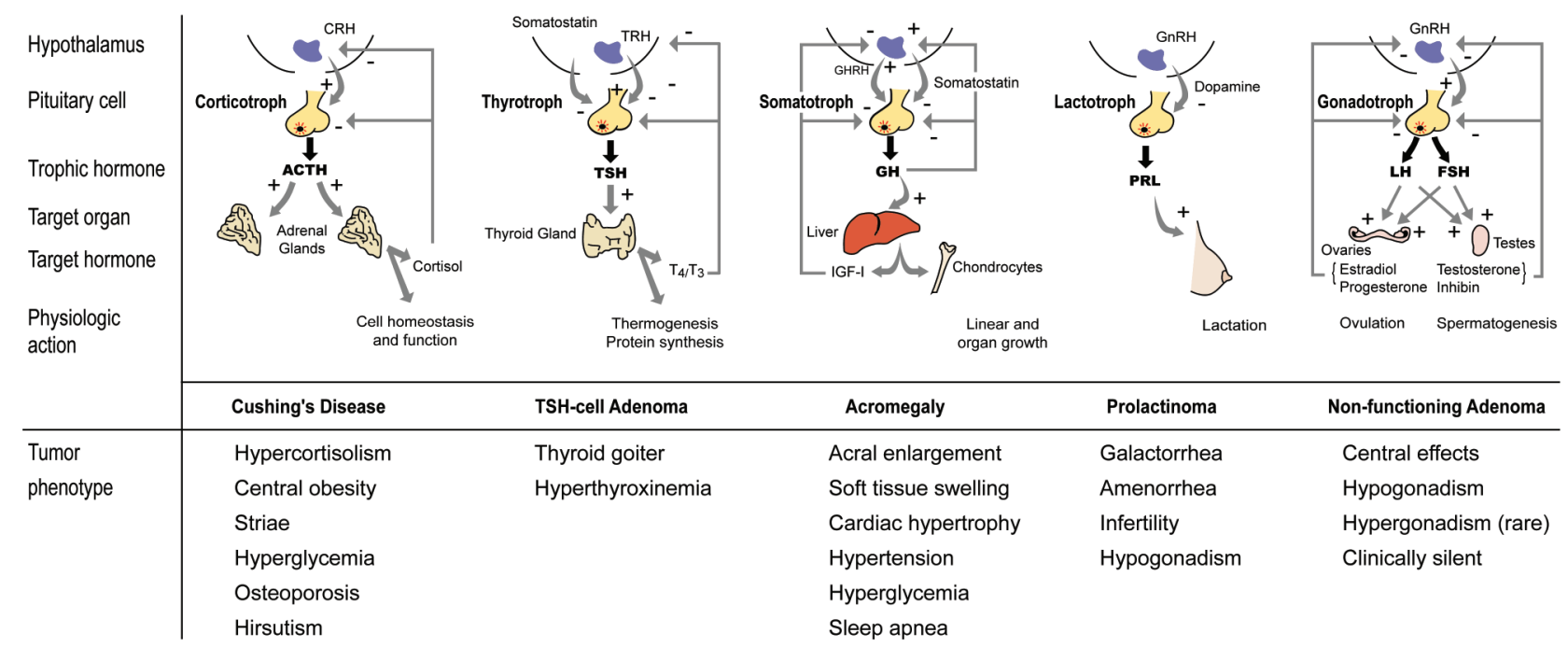

Figure 2

Hypothalamic-pituitary regulation and pituitary tumor pathogenesis.

poral and anatomic control of homeodomain repressor and activator transcription factor expression. Figure 1 depicts the developmental lineages of anterior pituitary subtypes (7). Functional disruption of this cellular cascade by transcription factor mutations may lead to hormone deficiencies due to disordered pituitary cell development and differentiation and resultant pituitary hypoplasia.

Early pituitary differentiation requires Rpx and Ptx expression. Ptx2 is mutated in patients with Rieger syndrome (8), which comprises maldevelopment of the anterior eye, teeth, and umbilicus, and GH deficiency. Lim homeobox (Lhx3) is defective in hypopituitary patients with features of a rigid cervical spine (9), and Lhx4 muta- tions are associated with combined pituitary hormone deficits in patients with Chiari-type cerebellar malformations (10). Rpx (Hesx 1) is critical for the development of a committed Rathke's pouch, and rare Rpx mutations are found in subjects with septo-optic dysplasia (midline forebrain abnormalities, optic nerve hypoplasia, and pituitary dysplasia) (11). A T-box factor (12), Tbx19/Tpit, interacts cooperatively with PitX1 in corticotrophs and loss of T-pit function has been reported in patients with isolated ACTH deficiency (13). T-pit disruption in transgenic mice also leads to hypoplasia of the proopiomelanocortin (POMC)-expressing intermediate lobe (14).

Developmental PROP-1 defects produce variable phenotypes and include defects in all five anterior pituitary

Table 1

Anterior pituitary hormone secretion and action

\begin{tabular}{|c|c|c|c|c|c|}
\hline & Gonadotroph & Thyrotroph & Lactotroph & Somatotroph & Corticotroph \\
\hline Fetal appearance & 12 weeks & 12 weeks & 12 weeks & 8 weeks & 6 weeks \\
\hline Hormone & FSH, LH & $\mathrm{TSH}$ & PRL & $\mathrm{GH}$ & POMC \\
\hline $\begin{array}{l}\text { Chromosomal gene } \\
\text { locus }\end{array}$ & $\beta-11 p ; \beta-19 q$ & $\alpha-6 q ; \beta-1 p$ & 6 & $17 q$ & $2 p$ \\
\hline Protein & $\begin{array}{l}\text { Glycoprotein } \alpha, \beta \\
\text { subunits }\end{array}$ & $\begin{array}{l}\text { Glycoprotein } \alpha, \beta \\
\text { subunits }\end{array}$ & Polypeptide & Polypeptide & Polypeptide \\
\hline$A A$ & $210 ; 204$ & 211 & 199 & 191 & 266 (ACTH 1-39) \\
\hline Stimulators & GnRH, estrogen & $\mathrm{TRH}$ & Estrogen, TRH & GHRH, GHS & $\begin{array}{l}\text { CRH, AVP, } \\
\text { gp-130 cytokines }\end{array}$ \\
\hline Inhibitors & Sex steroids, Inhibin & $\begin{array}{l}\mathrm{T} 3 \text {, } \mathrm{T} 4 \text {, dopamine, somato- } \\
\text { statin, glucocorticoids }\end{array}$ & Dopamine & Somatostatin, IGF, activins & Glucocorticoids \\
\hline Target gland & Ovary, testis & Thyroid & Breast, other tissues & $\begin{array}{l}\text { Liver, bones, other } \\
\text { tissues }\end{array}$ & Adrenal \\
\hline Trophic effect & $\begin{array}{l}\text { Sex steroid, follicle } \\
\text { growth, germ cell } \\
\text { maturation; M: } 5-20 \mathrm{IU} / \mathrm{I} \text {, } \\
\text { F (basal): 5-20 IU/I }\end{array}$ & $\begin{array}{l}\text { T4 synthesis and } \\
\text { secretion }\end{array}$ & Milk production & $\begin{array}{l}\text { IFG-I production, } \\
\text { growth induction, } \\
\text { insulin antagonism }\end{array}$ & Steroid production \\
\hline Normal range & $\begin{array}{c}\text { M: 5-20 IU/I, } \\
F \text { (basal): 5-20 IU/I }\end{array}$ & $0.1-5 \mathrm{mlU} / \mathrm{l}$ & $\mathrm{M}<15 \mu \mathrm{g} / \mathrm{l}, \mathrm{F}<20 \mu \mathrm{g} / \mathrm{l}$ & $<0.5 \mu \mathrm{g} / \mathrm{l}$ & ACTH: 4-22 pg/l \\
\hline
\end{tabular}

T3, triiodothyronine; T4, thyroxine; M, male; F, female, AVP, vasopressin. GHS, GH secretagogues. 
Table 2

Factors regulating human pituitary growth and tumor formation.

\begin{tabular}{|c|c|}
\hline & Factor \\
\hline \multicolumn{2}{|l|}{ Pituitary hypoplasia } \\
\hline Transcription factor mutation & Pit-1, Prop-1, T-pit \\
\hline Structural defect & Hesx1, Pitx2, Lhx3, Lhx4 \\
\hline Hypothalamic hormone disruption & GHRH receptor \\
\hline Idiopathic & GH deficiency \\
\hline \multicolumn{2}{|l|}{ Pituitary hyperplasia } \\
\hline \multicolumn{2}{|l|}{ Lactotroph } \\
\hline Pregnancy & Estrogen \\
\hline Lactation & Estrogen \\
\hline \multicolumn{2}{|l|}{ Excessive estrogen exposure } \\
\hline Stalk-section & D2R disruption \\
\hline \multicolumn{2}{|l|}{ Somatotroph } \\
\hline Eutopic or ectopic GHRH production & GHRH \\
\hline \multicolumn{2}{|l|}{$\begin{array}{l}\text { Hypothalamic tumor, chest and abdominal } \\
\text { carcinoid, phaeochromocytoma }\end{array}$} \\
\hline McCune-Albright syndrome & Gsp \\
\hline \multicolumn{2}{|l|}{$\begin{array}{l}\text { Mammosomatotroph hyperplasia } \\
\text { (gigantism) }\end{array}$} \\
\hline \multicolumn{2}{|l|}{ Corticotroph } \\
\hline Eutopic or ectopic $\mathrm{CRH}$ production & $\mathrm{CRH}$ \\
\hline \multicolumn{2}{|l|}{ Hypothalamic tumor } \\
\hline \multicolumn{2}{|l|}{ Thymic tumor } \\
\hline Untreated adrenal failure & Adrenal steroid feedback \\
\hline \multicolumn{2}{|l|}{ Cushing disease $(\sim 10 \%)$} \\
\hline \multicolumn{2}{|l|}{ Nelson syndrome } \\
\hline \multicolumn{2}{|l|}{ Thyrotroph } \\
\hline Untreated thyroid failure & Thyroid feedback \\
\hline \multicolumn{2}{|l|}{ Gonadotroph } \\
\hline Untreated gonadal failure & Gonadal steroid feedback \\
\hline \multicolumn{2}{|l|}{ Klinefelter syndrome } \\
\hline \multicolumn{2}{|l|}{ Pituitary adenoma } \\
\hline \multicolumn{2}{|l|}{ Hereditary } \\
\hline \multicolumn{2}{|l|}{ MEN-1 } \\
\hline \multicolumn{2}{|l|}{$\mathrm{CNC}$} \\
\hline Signal transduction mutations & $g s p$, CREB \\
\hline Loss of tumor suppressor gene function & $\mathrm{Rb}, \mathrm{p} 16, \mathrm{p} 27, \mathrm{GADD} 46 \gamma$ \\
\hline $\begin{array}{l}\text { Disrupted paracrine growth factor or } \\
\text { cytokine action }\end{array}$ & $\begin{array}{l}\text { FGFs, EGF, NGF, cytokines, } \\
\text { CAMS }\end{array}$ \\
\hline Chromosomal instability & PTTG \\
\hline Epigenetic events & Methylation, deacetylation \\
\hline
\end{tabular}

CAMS, cell adhesion molecules.

hormones (15). GH-, PRL-, and TSH-expressing cells share a common developmental pathway, and Pit-1 mutations can affect all three cell types. Ames dwarf (Prop $1^{d f / d f}$ ) and Pit-1 $1^{d w / d w}$ mice display growth deficiency, hypothyroidism, and infertility $(16,17)$. Inappropriate timing of pituitary transcription factor expression may also lead to developmental consequences. Persistent transgenic murine pituitary Prop-1 expression results in delayed murine gonadotrope differentiation, persistent Rathke's cleft cysts, pituitary enlargement, and null cell nonsecreting pituitary adenomas (18).

Pituitary growth is altered dramatically by transcription factor mutations (19). In a study of 52 patients with PROP-1 mutations assessed by MRI, the pituitary was found to be hypoplastic in 34, hyperplastic in 14, and normal in 4 subjects (19). Pituitary height, as assessed by MRI, was diminished in over two thirds of 76 patients with both idiopathic and genetic GH deficiencies due to GH, GHRH receptor, or PROP-1 deficiency (20). Interestingly, subjects with idiopathic GH deficiency, likely due to perinatal damage (hypoxia), exhibited pituitary stalk thinning with an ectopic posterior lobe, presumably reflecting functional hypothalamic disruption. Paradoxically, some patients with inherited multiple pituitary hormone deficiencies may in fact develop nonhomogenous cystic pituitary hyperplasia, which must be distinguished from a pituitary adenoma (21). This discordant pituitary growth may reflect enhanced sensitivity to a pituitary growth signal unmasked by PROP-1 disruption.

Although Pit-1 mRNA is increased up to fivefold in pituitary adenomas expressing GH and or PRL, the cell type distribution, size, and sequence of Pit-1 transcripts are unaltered from normal pituitary tissue (22). Ratios of adenoma Pit- 1 and Pit- $1 \alpha$ isoforms are also normal, further suggesting that pituitary tumorigenesis is not associated with altered Pit-1 expression. Human PROP-1 is persistently expressed beyond embryonic development, although prolonged expression is tumorigenic in transgenic mice (18). Persistent PROP-1 expression in both normal and adenomatous human pituitary tissue and the absence of PROP-1 coding mutations (23) from pituitary tumors suggest that this factor may be required to maintain mature pituitary cell types. Recently, a murine model of pituitary hypoplasia has been developed by the disruption of the cyclin-dependent kinase 4 (CDK4), leading to profound selective lactotroph hypoplasia (24).

Pituitary byperplasia. The pituitary gland responds to inducing signals, as well as their withdrawal, by regulating both trophic hormone secretion and mitotic and apoptotic growth changes. Pituitary hyperplasia is characterized by increased proliferation of a single cell type, which may be focal, nodular, or diffuse. There is an absolute increase in numbers of specific cells, with pituitary enlargement visible on MRI. Pituitary hyperplasia may range from modest cell type increases to large glandular expansion with grossly altered tissue architecture and morphology (25). The pathological diagnosis of hyperplasia is difficult and is best made by demonstrating intact acinar structures utilizing a reticulin stain. Specifically, corticotroph hyperplasia may be associated with Crooke's hyaline changes, and thyrotroph hyperplasia, with periodic acid Schiff-positive lysosomes. Rarely, pituitary hyperplasia may be of primary origin, and is 


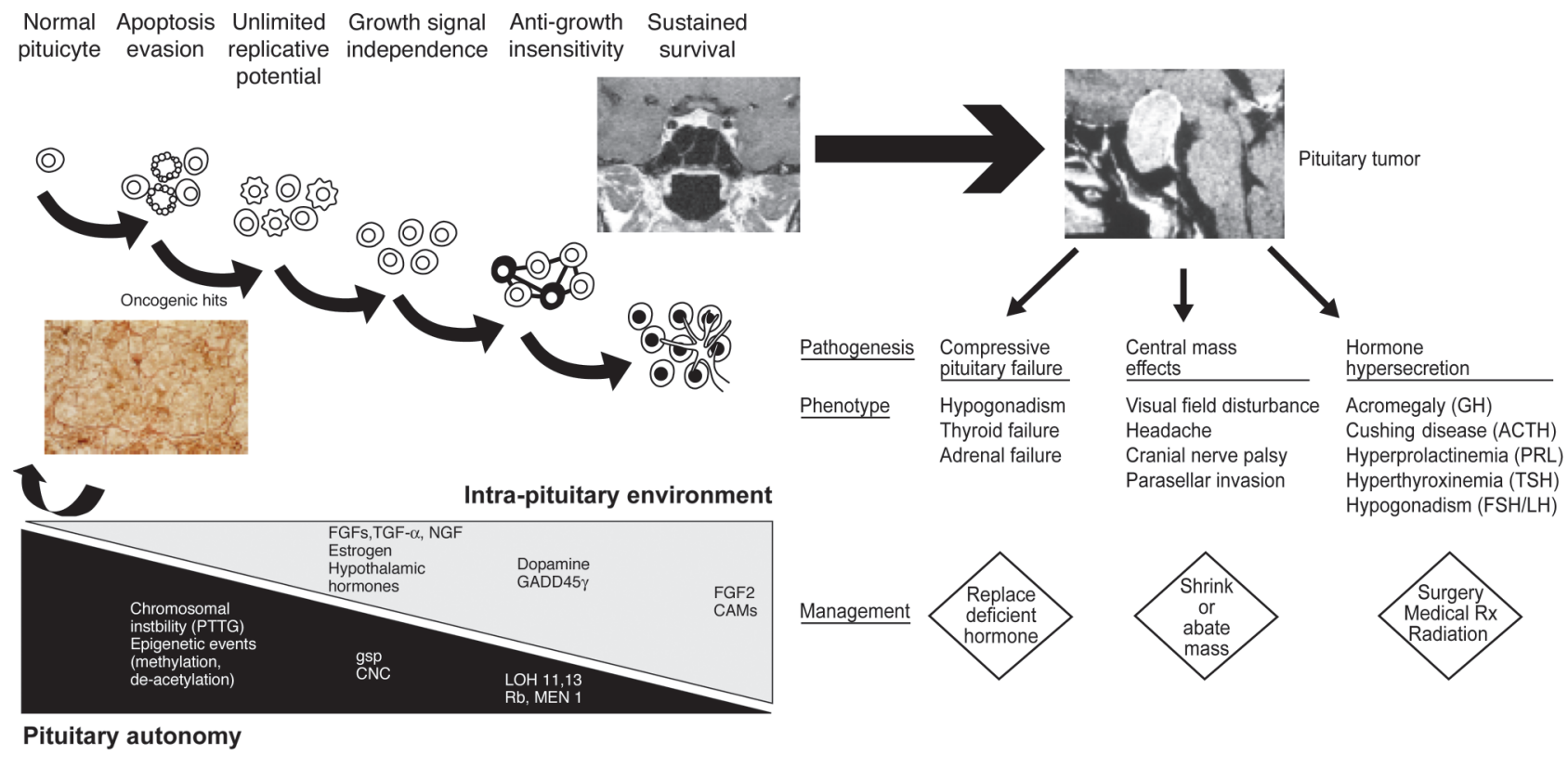

Figure 3

Pathogenesis of pituitary tumors. The spectrum of cellular changes leading from reversible hyperplasia to a committed pituitary microadenoma and ultimately to a macroadenoma. Pituitary cell types undergo proliferative and secretory changes as a consequence of a graded sequence of intrinsic and extrinsic signals. The cascade of growth-promoting signals and oncogenic "hits" may revert early, as observed with reversible pituitary hyperplasia (e.g., pregnancy or end-organ failure). Factors leading to enhanced pituicyte growth autonomy, with evasion of apoptosis and unrestrained replicative potential, are potentiated by intrapituitary changes in hormone, growth factor, or receptor functions. Figure based on a hypothesis proposed in (142). Rx, therapy.

usually secondary to extrinsic signals. Normal pituitary height as assessed by MRI is up to $9 \mathrm{~mm}$ in healthy subjects, while adolescent females tend to have larger pituitary glands. Clearly, hormonal and clinical evaluations are required for all enlarged pituitary images, as "primary" pituitary enlargement is rarely encountered, especially in male subjects. Invariably, an enlarged pituitary discovered incidentally on MRI can be ascribed to a pituitary adenoma (26).

Target hormones (sex and adrenal steroids, and thyroid hormones) exert powerful negative feedback inhibition of their respective trophic hormone gene transcription and hormone secretion, as well as suppression of pituicyte growth. Failure of target glands (thyroid, adrenal, and gonads) leads to loss of negative feedback inhibition and resultant compensatory hyperplasia of the respective pituitary trophic hormone cells (Figure 2). Thus, longstanding primary hypothyroidism, hypogonadism, or hypoadrenalism may be associated with a clinically enlarged pituitary gland visible on MRI, with involution of the gland occurring after appropriate target hormone replacement and restoration of negative feedback (Figure 3).

The pituitary gland enlarges approximately twofold during pregnancy with most growth accounted for by diffuse lactotroph hyperplasia. Pre-existing lactotrophs proliferate, and somatotrophs are also recruited to switch from GH to PRL production (27). After birth or cessation of lactation, the pituitary size involutes and hyperactive "pregnancy cells" regress, and the number of lactotrophs reverts to almost normal. Nevertheless, both pituitary weight and cell numbers are higher in nonpregnant multiparous women with no demonstrable increased incidence of prolactinoma formation (28). Interestingly, in postmenopausal women, despite enhanced gonadotropin (FSH and LH) production due to loss of ovarian function, the pituitary gland is usually small.

Since the original observations of absent or minimal true mitotic activity in hyperplastic pituitary glands (29), the origin of hyperplastic cells has been debated. Although the origin of most such entities has been ascribed to expanded clones arising from a stem cell, several lines of evidence support the concept of "reversible transdifferentiation" whereby cells are recruited from heterologous cell types (30). Early in development, GH-secreting cells have the capacity to transdifferentiate to gonadotrophs (31). Reversible phenotypic switching of GH and PRL gene expression has long been reported in experimental rat pituitary tumor cells (32), and is reflective of a common acidophilic stem cell precursor for both PRL and GH cells. Several rodent models of pituitary hyperplasia exist, including pregnancy and administered antithyroid medication; these exhibit plastic interchange of PRL and GH, as well as TSH- and GH-secreting cell populations, respectively. In humans, during pregnancy, lactotroph cells are recruited from $\mathrm{GH}$-secreting cells, and the hyperplastic cell population may be bihormonal, secreting both hormones. Similarly, hypothyroid patients exhibit thy- 
rotroph hyperplasia with recruitment of GH-secreting cells, leading to bihormonal TSH- and GH-cell hyperplasia (33). It is unclear whether these bihormonal, hypertrophic cells arise as a consequence of transdifferentiation of already committed cells, or whether earlier more primitive stem cells undergo expansion.

Several lines of evidence corroborate the concept of a hypothalamic role for pituitary tumorigenesis. True pituitary adenomas often retain the capacity to respond to hypothalamic trophic stimuli. Furthermore, pituitary adenomas, especially prolactinomas, may resolve spontaneously, demonstrating the plasticity of adenomatous pituitary cell growth (6). Finally, the clear demonstration of pituitary tumor mass shrinkage in patients receiving somatostatin analogs for acromegaly or dopaminergic therapy for prolactinomas $(34,35)$ supports the notion that some of the transformed pituitary cells retain a measure of hypothalamic control, with the capacity to reverse adenoma growth.

Estrogen. Lactotroph hyperplasia is encountered in rodents and humans receiving high estrogen doses, and several models of estrogen action provide insight into the role of hyperplasia as a precursor for pituitary adenoma formation. Estrogen is mitogenic for lactotrophs and gonadotrophs, and is a ligand for the estrogen receptor (ER) encoded by two genes: $E R \alpha$, expressed in $70-100 \%$ of prolactinomas, and ER $\beta$, detectable in $60 \%$ of these tumors (36). Estradiol ligand binding leads to activation of estrogen-responsive genes, with a stronger estrogen response due to ER $\alpha$ than to ER $\beta$. High doses of estrogen induce rat lactotroph hyperplasia and adenoma formation (37), and prenatal murine exposure to diesthylstilbestrol markedly enhances prolactinoma development in female offspring (38). The female preponderance of prolactinomas and their increased size during pregnancy may be ascribed to high estradiol levels, especially since prolactinomas express estrogen receptors most abundantly. In addition to cell trophic effects, estrogen induces the prolactin promoter, and activates the pituitary tumor transforming gene (PTTG), FGF- $\beta$, FGF- $\beta$ receptors, and TGF- $\beta$ and $\alpha$ expression, all of which are implicated in pituitary tumorigenesis. Alternatively spliced ER $\alpha$ mRNAs

\footnotetext{
Figure 4

In vivo estrogen induction of PTTG and rat lactotroph tumors. (a) Representative normal rat pituitary $(\mathrm{NI})$ and rat pituitary tumor $\left(\mathrm{E}_{2}\right)$. (b and c) Serum PRL and pituitary wet weight (b) and Northern blot analysis (c) of pituitary tissue extracts derived from estrogen-treated rats. $\beta$-Actin was utilized as the internal control. Ovx, ovariectomized controls. $M$, marker lane. ${ }^{*} P<0.001 ;{ }^{*} P<0.01$. (d and $\mathbf{e}$ ) Reticulin fiber staining (broken circle) of rat anterior pituitary tissue at 24 hours (d) and 1 week (e) after commencement of estrogen infusion. (f and $\mathbf{g}$ ) Reticulin stain (arrows) (f) and hematoxylin and eosin stain ( $g$ ) of rat anterior pituitary tissue 4 weeks after estrogen infusion began. Widespread vacuolation, vascular lakes (g, arrow), nuclear pleomorphism and frequent mitosis (g, arrowhead) are visible. (h) pituitary bFGF immunoreactivity after 4 weeks of estrogen treatment. Original magnification, $\times 200$. Reproduced with permission from Nature Medicine (37).
}

encode isoforms with altered responsiveness to estrogens and antiestrogens, suggesting a mechanism for tumorigenesis. ER transcripts with deletions of exons 2 and 5, which behave as stimulatory or ligand-independent isoforms, have been detected in nearly all prolactinomas. In contrast, deletions that encode dominant negative ER $\alpha$ isoforms lacking DNA binding or transactivation functions, respectively (exon 7), are less commonly encountered in prolactinomas $(36,39)$. PTTG is expressed in the female rat pituitary in an estrous cycle-dependent fashion, suggesting PTTG involvement in pituicyte proliferation after proestrous (40). Rat pituitary expression of PTTG is induced early by estrogen and precedes estrogen-induced pituitary hyperplasia and adenoma formation (Figure 4). Antiestrogens attenuate pituitary expression of PTTG concomitantly with their blocking of the cellular effects of estrogen (41), and these agents also block pituitary tumor cell proliferation in vitro and in vivo (41). Although animal models depict estrogen-induced pitu-
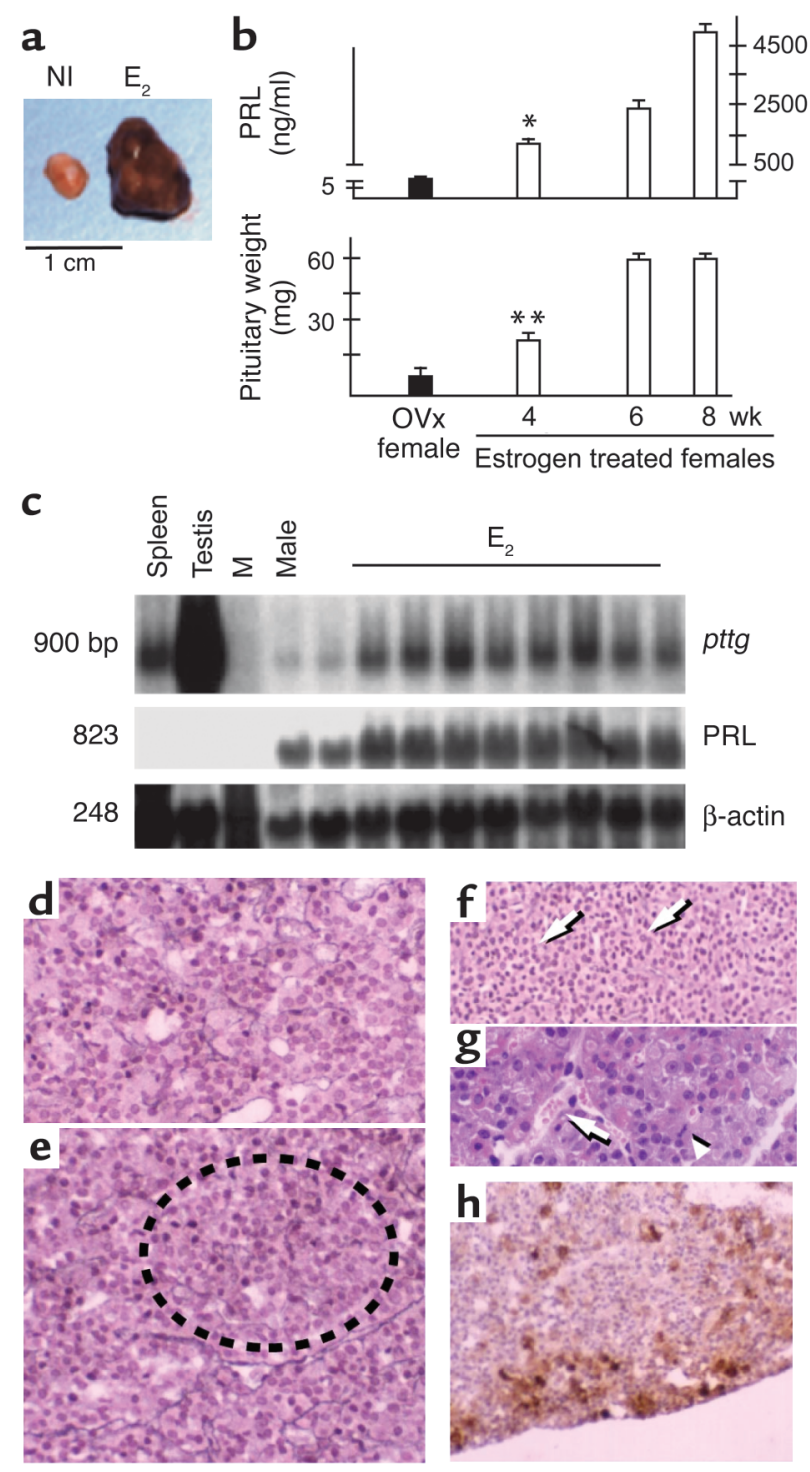
itary hyperplasia as preceding adenoma formation, only rare cases of prolactinoma formation have been reported in patients receiving high estrogen doses. A transsexual patient exposed to excess estrogen (42) and a young female with lactotroph hyperplasia (43) were reported to have developed coexistent prolactinomas.

Hypothalamic signaling. Generalized pituitary hyperplasia would be expected if the adenomatous growth were induced in response to hypothalamic hormone overstimulation. The hypothalamus secretes hormones through the portal vein; these factors impinge upon anterior pituitary cells to regulate anterior pituitary hormone synthesis and secretion (Figure 2). Disrupted stimulatory hypothalamic signals or defects in their cognate anterior pituitary receptors leads to pituitary hormone deficiencies. Mice with disrupted corticotropin-releasing hormone (CRH) (44) have impaired ACTH synthesis. In transgenic rodents, pituitary hyperplasia together with adenoma formation is observed in conjunction with overexpressed hypothalamic growth factors, including CRH or GHRH $(45,46)$, or those pituitaries deprived of dopamine inhibition, as observed in mice with a disrupted dopamine $\mathrm{D} 2$ receptor (DRD2) transgene (47). In contrast, human pituitary hyperplasia and hormone hypersecretion associated with rare hypothalamic or ectopic GHRH- or CRH-producing tumors (especially carcinoids) or Nelson syndrome are very rarely associated with adenoma development, suggesting that hyperplasia is not a prerequisite for adenoma development (47-51). In contrast, sporadic nonfunctioning pituitary tumors ( $\alpha$ subunit positive) or prolactinomas are commonly well circumscribed, and the surrounding pituitary tissue is usually normal or even hypoplastic.

Hypothalamic dopamine exerts tonic inhibition of PRL synthesis and secretion as well as lactotroph proliferation, and DRD2 mediates these actions. Focal lactotroph hyperplasia is encountered when the pituitary is deprived of hypothalamic dopamine, as seen with compressive stalk disruption by a parasellar mass or pharmacologic dopamine antagonism. Drd2-disrupted mice are not responsive to dopamine, and develop lactotroph hyperplasia and ultimately prolactinomas (51). Prolonged lactotroph hyperplasia (for up to 18 months) precedes adenoma development in female $\operatorname{Drd2} 2^{-/-}$mice, likely by allowing an enlarged pool of lactotrophs to acquire initiating tumorigenic changes; alternatively, pituitary hyperplasia might not be a prerequisite for tumorigenesis. Clinically, dopamine agonist resistance in patients with prolactinomas reflects reduced adenoma dopamine receptor expression. However, in one study, the DRD2 gene was not mutated in human pituitary tumors, in 46 prolactinomas, and in 19 mixed GH/PRL adenomas (52).

Somatostatin membrane receptors are encoded by five distinct somatostatin receptor (SSTR) subtypes (SSTR1-SSTR5), and SSTR2 and SSTR5 are mainly involved in mediating GH suppression. Patients exhibiting resistance to somatostatin analog therapy for acromegaly have demonstrated decreased tumor receptor expression, although inactivating mutations in the genes encoding SSTR 2 and SSTR 5 are uncommonly encountered $(53,54)$.

Hypothalamic TRH stimulates TSH thyrotroph release and lactotrophs. Although mutations in the TRH receptor gene were not detected in 50 pituitary adenomas, a mutated ligand-binding domain of thyroid hormone receptor $\beta$ (TR $\beta$ ) was reported in a TSHsecreting adenoma resistant to thyroid hormone (55); the gonadotrophin-releasing hormone receptor $(G n R H-R)$ gene sequence was normal in 10 tumors. Despite extensive searches, activating mutations in hypothalamic hormone receptor genes (including GHRH-R, GnRH-R, TRH-R, D2R, SSTR2, and SSTR5) are rarely observed in human pituitary tumors (56-58).

GHRH signaling defects. GHRH is required both for somatotroph differentiation and proliferation and for regulation of GH expression. GHRH induces GH gene transcription and release, and also stimulates somatotroph cell DNA synthesis $(59,60)$. Inactivating defects in the pituitary GHRH receptor, identified in the little mouse strain (61) are similarly associated with pituitary hypoplasia, GH deficiency, and short stature in humans. Although activating GHRH mutations with constitutive activation of the cAMP signaling pathway have been excluded in somatotropinomas (58, 62), mutations of several key GHRH signaling pathways have been associated with pituitary hyperplasia and tumor pathogenesis.

Gsp mutations. The McCune-Albright syndrome comprises asymmetric defects in bony skeleton and skin (precocious puberty, thyrotoxicosis, acromegaly, gigantism, or Cushing syndrome). Pituitary lesions are usually hyperplastic and are less commonly adenomatous. The molecular defect in McCune-Albright syndrome is the activating gsp mutation in the GNAS1 gene (guanine nucleotide-activating $\alpha$ subunit) identified on chromosome 20q13.2, which bypasses ligand-dependent signaling (63), resulting in constitutive hormone gene activation.

The gsp mutation identified in McCune-Albright syndrome also occurs in approximately $30 \%$ of sporadic $\mathrm{GH}$-secreting tumors with constitutively activated $\mathrm{G}_{\mathrm{s}} \alpha$ protein-stimulating adenylate cyclase (64). Reduced GTPase activity leads to stabilization of the active form of the $G_{s} \alpha$ protein and increased adenylyl cyclase activity. Increased cAMP caused by $g s p$ enhances GH secretion independently of hypothalamic GHRH ligand. The oncogenic gsp mutation correlates with constitutively increased cAMP response element-binding protein (CREB) phosphorylation and activity (65) leading to increased Pit-1 transcription, and enhanced GH synthesis. Targeted CREB deletion in transgenic mice leads to somatotroph cell depletion and dwarfism (66). However, additional mechanisms inducing CREB phosphorylation appear to be required, as one study demonstrated that 6 of $15 \mathrm{GH}$ secreting tumors had altered $G_{s} \alpha$ gene sequences or expression levels, while all GH-secreting tumors stud- 
Table 3

Pathologic and clinical characteristics of pituitary adenomas.

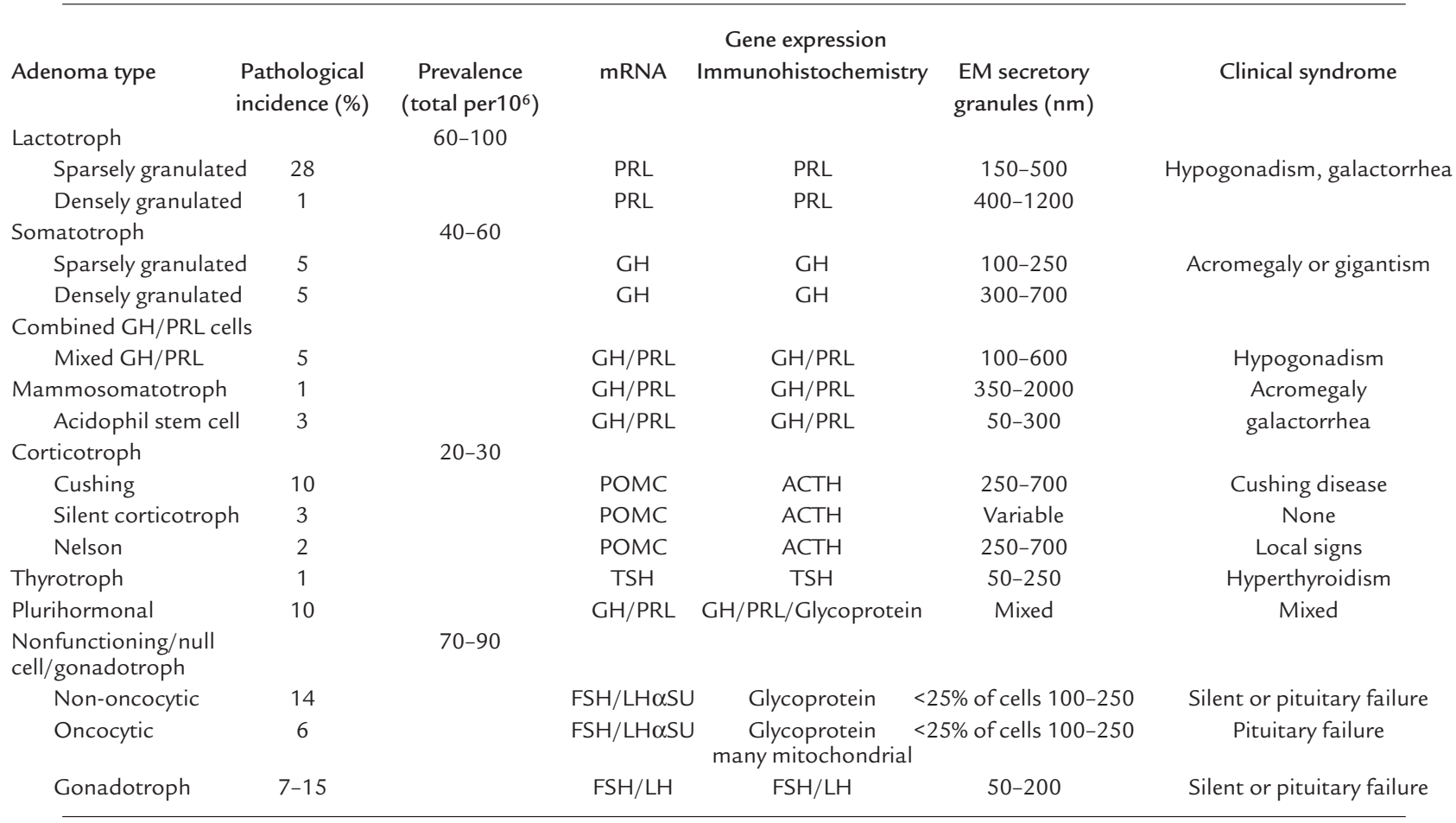

Data are derived from studying a relatively stable 1 million catchment population surrounding Stoke-on-Trent, United Kingdom (144-148). Modified with permission from W.B. Saunders (139).

ied had increased phosphorylated CREB, compared with nonfunctioning pituitary adenomas (65).

As phosphodiesterase activity is also elevated approximately sevenfold in $g s p$-positive pituitary adenomas, the effects of elevated intracellular cAMP levels appear to be counteracted by additional intracellular mechanisms (67). Intriguingly, there are few in vivo phenotypic features distinguishing GH-cell adenomas bearing the gsp mutation. Gsp-positive tumors show enhanced responsiveness to octreotide, a somatostatin analog, and can be biochemically controlled even when a tumor remnant is present after surgery.

Carney complex. The Carney complex (CNC) syndrome comprises cardiac myxomas, spotty skin pigmentation, and tumors of the adrenal gland and anterior pituitary. Pituitary lesions are hyperplastic, with multifocal microadenomas usually arising from GHcells. CNC exhibits genetic heterogeneity, mapping to two chromosomal regions. Families with a putative 2p16 defect exhibit tumor chromosome instability. The $17 \mathrm{q} 24$ gene, $C N C 1$, encodes protein kinase A (PKA) type I- $\alpha$ regulatory subunit (PRKAR $1 \alpha$ ) (68). Truncated PRKAR $1 \alpha$ is detectable in families with CNC linked to $17 \mathrm{q} 24$. PRKAR1 $\alpha$ defects likely act through haploinsufficiency, with an altered ratio of the PKA regulatory $\alpha$ and $\beta$ subunits resulting in lower basal PKA activity but increased PKA responses to cAMP stimulation in CNC tumors (69). As with multiple endocrine neoplasia type I (MEN I), some families with CNC exhibit only a subset of tumor types, with defects in PRKAR1 $\alpha$ also identified in isolated familial cardiac myxomas (70).

Pituitary adenomas in both McCune-Albright syndrome and CNC tend to be multifocal and are often preceded by hyperplasia, similar to those observed in animal models expressing excess GHRH. The GHRH signaling pathway may therefore be implicated at several levels leading to pituitary tumorigenesis. GH-producing tumors arise in transgenic mice overexpressing GHRH, and GH-cell adenomas express activating G protein $\alpha$-subunit mutations or inactivating mutations of PRKAR1 $\alpha$. Elevated cAMP levels lead to enhanced CREB phosphorylation, with subsequent activation of GH transcription and somatotroph cell transformation. Functional inactivation of CNC1-encoded PRKAR1 $\alpha$ enhances cAMP sensitivity.

Growth factors. Several pituitary-driven growth factors have been shown to induce pituitary hyperplasia with or without ultimate adenoma development when expressed in transgenic mice.

$b F G F$. FGF- $\beta$ is abundantly expressed in the pituitary and brain, induces angiogenesis, and is also a potent mitogen for neuroectoderm cells. FGF- $\beta$ synthesis is induced in NIH3T3 cells overexpressing PTTG. During the hyperplastic phase, prior to the development of prolactinomas (37), pituitary expression of both PTTG and FGF- $\beta$ is increased in a time- and dose-dependent manner in estrogen-treated rats.

Hst. The heparin-binding secretory transforming gene hst, encoding FGF-4, was identified from human 
sequences derived from prolactinoma DNA and was shown to be transforming in NIH3T3 cells (71). GH4 cells transfected with hst form tumors that are more aggressive when transplanted, and FGF-4 stimulates lactotroph proliferation and prolactin transcription and secretion (72). About $30 \%$ of human prolactinomas selectively express strong FGF-4 immunoreactivity (73), and FGF-4 abundance correlates with tumor invasiveness. A truncated FGF receptor isoform has also been shown to result in lactotroph tumors in transgenic mice when driven by the prolactin promoter (74).

TGFs. Pituitary TGF- $\alpha$ mRNA levels increase before initiation of lactotroph hyperplasia by estrogen administration. Transgenic female mice with pituitary TGF- $\alpha$ transgene expression driven by the PRL promoter develop lactotroph hyperplasia and, ultimately, prolactinomas by 12 months of age (75). TGF effects are likely potentiated in vivo by estrogen, and TGFs do not appear to induce other pituitary cell type tumors. TGF- $\beta$ is a pituitary growth inhibitor, and the estrogen receptor has been shown to coimmunoprecipitate with Smad4 and Smad1, implicating a TGF- $\beta$ interaction with estrogen in the pathogenesis of prolactinoma pathogenesis. (76).

NGF. Mammosomatotroph pituitary cells express NGF and its receptors. Mice, in which transgenic NGF is driven by the prolactin promoter, develop lactotroph hyperplasia without adenomas, despite having markedly enlarged pituitary glands (77).

Pituitary adenoma. Pituitary adenomas are common benign monoclonal neoplasms accounting for approximately $15 \%$ of intracranial tumors, while occult adenomas are discovered in as many as $25 \%$ of unselected autopsies. Pituitary tumors are usually benign, but cause significant morbidity due to their critical location, expanding size, and/or inappropriate pituitary hormone expression. Local compressive effects include headaches, visual disorders, cranial nerve dysfunction and/or altered hormone expression due to pituitary stalk disruption with compromised hypothalamic hormone access, and pituitary failure due to compression of normal pituitary tissue. Factors underlying pituitary tumorigenesis include both intrinsic pituicyte alter- ations and altered availability of regulatory factors including hypothalamic hormones, peripheral hormones, and paracrine growth factors.

Reflective of the specific cell type origin of the adenoma, unique clinical features are determined by the specific hormone hypersecreted (Table 3). Somatotropinomas overexpress $\mathrm{GH}$, causing acromegaly in adults, with bony acral changes in soft tissues and bone, and increased risk of hypertension, cardiac disease, and diabetes. Prolactinomas are the most common of all functional pituitary adenomas, and patients harboring prolactinomas overexpressing PRL usually present with amenorrhea, infertility, and galactorrhea in females, and impotence or infertility in males. Tumors expressing both PRL and GH may originate from a common mammosomatotroph precursor cell. Corticotropinomas lead to ACTH hypersecretion (Cushing disease) and adrenal steroid overstimulation. Features of hypercortisolism include truncal obesity, striae, muscle wasting, hirsutism, cardiovascular complications, osteoporosis, and psychiatric disturbances. Pure gonadotropinomas secreting intact FSH or LH are rarely encountered and may cause sexual dysfunction and hypogonadism. Thyrotropinomas cause a mild increase in thyroxine levels with inappropriate TSH levels.

The etiology of these tumors is unresolved and likely involves multiple initiating and promoting factors. The literature is replete with heterogenous descriptions of overexpressed or underexpressed specific oncogenes or growth factors in these adenomas, and they may not necessarily be the direct cause of the tumor, especially as many of these factors are induced only after cells are transformed (78) and may in fact be epiphenomena rather than etiologic molecules.

Clonality of anterior pituitary tumors. Abundant evidence suggests that pituitary adenomas are derived from clonal expansion of mutated somatic cells $(79,80)$. Evidence supporting this "intrinsic defect" hypothesis includes the observed well-circumscribed discrete adenomas surrounded by normal nonhyperplastic tissue, as well as results of X-inactivation studies and loss-of-heterozygosity $(\mathrm{LOH})$ analysis. Most pituitary tumors likely ini-

\section{Table 4}

Genetic syndromes involving pituitary tumors.

\begin{tabular}{|c|c|c|c|c|c|}
\hline Syndrome & Clinical Features & $\begin{array}{l}\text { Chromosome } \\
\text { location }\end{array}$ & Gene & Protein & Proposed function/defect \\
\hline MEN I & $\begin{array}{l}\text { Parathyroid, endocrine pancreas, } \\
\text { anterior pituitary (mostly } \\
\text { prolactinomas) tumors }\end{array}$ & $11 q 13$ & MEN1 & MENIN & $\begin{array}{l}\text { Nuclear, tumor suppressor protein } \\
\text { interacts with junD }\end{array}$ \\
\hline $\begin{array}{l}\text { Familial } \\
\text { acromegaly }\end{array}$ & $\begin{array}{l}\mathrm{GH} \text {-cell adenomas, } \\
\text { acromegaly/gigantism }\end{array}$ & $\begin{array}{l}11 \mathrm{q} 13 \text { and } \\
\text { other loci }\end{array}$ & Not men1 & --- & --- \\
\hline $\begin{array}{l}\text { McCune-Albright } \\
\text { syndrome }\end{array}$ & $\begin{array}{l}\text { Polyostotic fibrous dysplasia, } \\
\text { pigmented skin patches; endocrine } \\
\text { abnormalities: precocious puberty, } \\
\text { GH-cell adenomas, acromegaly/ } \\
\text { gigantism Cushing syndrome }\end{array}$ & $\begin{array}{l}20 q 13.2 \\
\text { (mosaic) }\end{array}$ & GNAS1 (gsp) & $\mathrm{G}_{s} \alpha$ & $\begin{array}{l}\text { Signal transduction/inactive GTPase } \\
\text { results in constitutive cAMP } \\
\text { elevation independent of GHRH }\end{array}$ \\
\hline CNC syndrome & $\begin{array}{l}\text { Skin and cardiac myxomas, } \\
\text { Cushing disease, acromegaly }\end{array}$ & $2 p 16$ & --- & --- & PKA signaling defect for activating $\mathrm{GH}$ \\
\hline
\end{tabular}

Adapted with permission from (149). 
tiate with expansion of a single cell, as they exhibit nonrandom methylation patterns. Occasionally, multifocal polyclonal pituitary adenomas associated with hyperprolactinemia may arise either due to extrinsic changes in hypothalamic factors, or to pituitary stalk compression, blocking lactotroph inhibition by dopamine.

Familial pituitary tumor syndromes. Three specific genes have been identified that predispose to pituitary tumorigenesis, including MEN I, CNC, and McCune-Albright syndrome (Table 4). Four pedigrees in which MEN I was excluded have been reported with isolated prolactinomas (81). Linkage analysis and MEN I mutation screening show that familial hyperprolactinemia is genetically distinct from MEN I. Although isolated familial GHsecreting adenomas are linked to at least two chromosomal regions, $11 \mathrm{q} 13$ and a distinct locus unrelated to $11 \mathrm{q} 13$, mutations of $M E N I$ have been excluded in these families $(82,83)$. Interestingly, early onset familial acromegaly has been linked to $11 \mathrm{q} 13$ and $2 \mathrm{p} 16$, chromosomal loci for both MEN I and CNC genes.

$\mathrm{LOH}$ and the role of tumor suppressor genes. Using genome-wide scanning and allelotyping with 122 microsatellite markers in 100 nonfunctioning and GHsecreting adenomas, multiple hot-spots have been detected, suggesting widespread $\mathrm{LOH}$ with enhanced susceptibility to epigenetic events (84). Deletions of chromosomal loci, including 11q13,9p, 10q, and $13 q 14$, occur in $12-30 \%$ of invasive pituitary tumors (85). Retention of heterozygosity has also been reported in subsequent tumor tissue whose earlier specimens displayed LOH. However, few of these tumors were examined for $\mathrm{X}$-inactivation, to confirm the clonal populations, and in some, contamination by adjacent normal pituitary tissue was not rigorously excluded.

MEN I. The familial syndrome MEN I affects the parathyroid gland and endocrine pancreas, and, less frequently, the anterior pituitary, with mostly prolactinomas. MEN I behaves as an autosomal dominant trait with reduced penetrance. MEN1 encodes a 610amino-acid nuclear protein, MENIN, which interacts with JunD to repress transactivation. The chromosome 11 q13 germline mutation is unmasked by a "second somatic hit" on the remaining allele and is visualized as $\mathrm{LOH}$ for polymorphic DNA markers spanning the MEN1 gene. The "two-hit" requirement for phenotypic expression is also consistent with the presence of truncated MEN1 mutations present in up to $85 \%$ of MEN I families. Transgenic mice bearing a Men1 heterozygous disruption recapitulate the human MEN I syndrome (86). Heterozygotes develop tumors with LOH of the wild-type chromosome, including pancreatic ( $40 \%$ by 9 months), parathyroid (24\% by 9 months), and pituitary ( $26 \%$ by 16 months) tumors.

The role of MEN1 mutations in pituitary tumorigenesis in humans is not readily apparent. The preponderance of prolactinomas occurring in familial MEN I suggests that pituitary tumors might be caused by kindred-specific mutations. Furthermore, pituitary tumors develop with varying frequency in obligate carriers of $M E N 1$ mutations.
As $\mathrm{LOH}$ for $11 \mathrm{q} 13$ is observed in up to $30 \%$ of sporadic pituitary tumors (especially invasive), a role for $M E N 1$ in the progression but not the initiation of sporadic pituitary tumors has been suggested. However, sequence analysis shows that MEN1 mutations occur in less than $2 \%$ of sporadic pituitary adenomas. Although reduced MEN1 expression has been observed with decreased copy number, the overwhelming majority of sporadic pituitary tumors express both MEN1 alleles equally, excluding genomic imprinting as a general mechanism to silence this chromosomal region (87). Taken together, evidence from studies of sporadic pituitary tumors predicts the putative presence of a distinct tumor suppressor gene for these adenomas in the $11 \mathrm{q} 13$ region.

$R b$. The retinoblastoma protein $\mathrm{Rb}$, a key cell cycle regulator, is differentially phosphorylated by cell cycle-dependent kinases and cyclins (88). Activated hypophosphorylated Rb binds E2F, blocking entry into the cell cycle and suppressing proliferation, while phosphorylated $\mathrm{Rb}$ releases E2F. Transgenic mice with disrupted $R b$ do not develop retinoblastoma, but surprisingly exhibit large pituitary tumors arising from pituitary ACTH-producing cells in the intermediate lobe (89). This observation led to a search for $R b$ as a candidate for involvement in human pituitary tumors. Although LOH for polymorphic markers on chromosome $13 \mathrm{q} 14$ is detected in aggressive pituitary tumors and their metastases, immunoreactive $\mathrm{Rb}$ protein is still detectable. Several lines of evidence indicate that $\mathrm{Rb}$ itself is not implicated in pituitary tumorigenesis. First, the $R b$ locus was demonstrated to be intact in more than 50 benign pituitary adenomas $(90,91)$. Wild-type hypophosphorylated (active) Rb has been detected in a large cohort of 24 pituitary tumors, and single-strand conformational polymorphism mobility shifts indicative of sequence changes were not detected for exons 20-24, which encode the pocket domain (92). These results are suggestive of a distinct tumor suppressor gene on 13q14 unmasked by LOH in aggressive sporadic pituitary tumors. Some reports indicate that $\mathrm{Rb}$ expression might be decreased by promoter methylation in a subset of invasive pituitary tumors.

p27. Mice disrupted for $p 27$ develop enhanced growth, with multiorgan hyperplasia and increased cell proliferation. Intriguingly, these mice frequently develop tumors of POMC-positive cells of the pituitary intermediate lobe (93). The $p 27$ gene behaves as a tumor suppressor gene both in animal models and also in sporadic human pituitary tumors. Immunodetectable p27 protein is underexpressed or absent in most human pituitary tumors, and is undetectable in rare pituitary carcinomas (94). Pituitary adenoma expression of $\mathrm{p} 27$ is likely regulated by post-transcriptional and post-translational mechanisms, including ubiquitin-dependent protein degradation (95), and p27 mutations have been excluded in these tumors. Doubly disrupted $p 27$ and $R b$ mice have enhanced pituitary tumor development, and $\mathrm{p} 27$ loss retards apoptosis in $R b^{-/-}$tumor cells (96). Galectin-3, which induces p 27 , is 
a

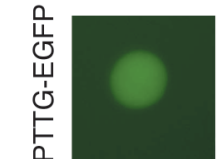

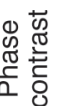

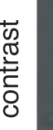

믄
Live cell image

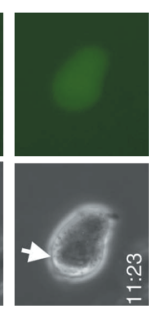

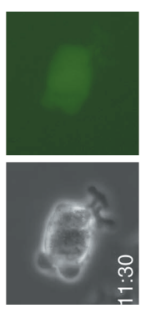

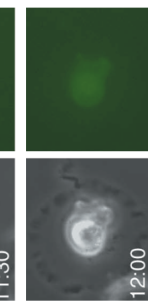

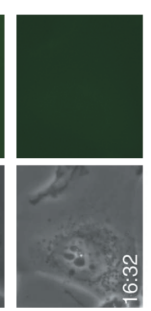

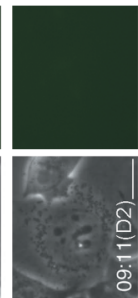

b

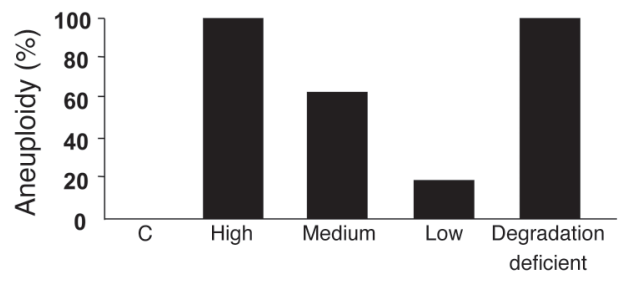

PTTG expression

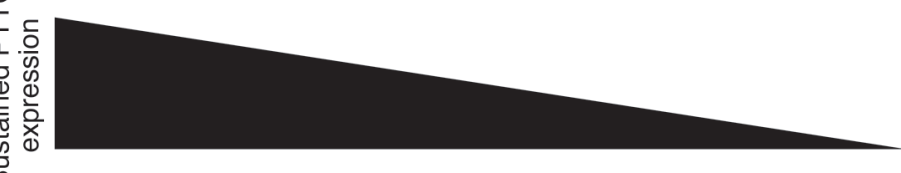

\section{Figure 5}

Chromosome nonsegregation and aneuploidy results from failure of PTTG-EGFP fusion protein degradation after transfection of a degradation-deficient PTTG mutant. (a) Single live H1299 cells with persistent PTTG-EGFP expression were continuously observed and show absence of chromosome segregation with completed cytokinesis. Phase contrast (bright field) and PTTG-EGFP images (green) are shown; D2, second day of observation. Arrow, cell entering mitosis. Scale bar, $10 \mu \mathrm{m}$. (b) Aneuploidy correlation with transfected PTTG expression levels or with failure to degrade PTTG in a degradation-deficient mutant. C, control. Panel a modified with permission from Endocrinology (129).

upregulated in neoplastic pituitary tissue derived from p27-null mice, and inhibition of galactin-3 expression decreases pituitary tumor cell proliferation (97).

p18. Disruption of the cyclin inhibitor gene $p 18^{\text {Ink } 4 c}$ results in widespread organomegaly and pituitary hyperplasia, with ACTH-cell intermediate lobe tumors (98). GH levels are normal and IGF-1 is only slightly elevated in these animals, indicating that tissue overgrowth is likely due to an intrinsic p18 defect rather than endocrine hypersecretion. The powerful suppressive effect of CDK inhibitors on pituitary cell growth and tumorigenesis is exemplified by disruption of both p18 and p27, leading to synergistic development of pituitary tumors, with greatly accelerated pituitary tumorigenesis (99).

p16. The protein $\mathrm{p} 16^{\mathrm{Ink} 4 \mathrm{a}}$, encoded by the CDKN2A gene on chromosome $9 \mathrm{p} 21$, maintains $\mathrm{Rb}$ in an unphosphorylated, active state by blocking CDK4. There was no detection of $\mathrm{p} 16$ by Western blot analysis of 25 pituitary tumors (95), and homozygous $p 16$ gene deletions have been described in pituitary adenomas. Moreover, p16 also appears to be inactivated in pituitary adenomas by methylation, and introduction of inducible p16 into AtT20 murine ACTH-secreting cells caused reversible growth inhibition and G1 arrest (100).

$p 53$. Although $p 53$ is commonly mutated in human tumors, it does not appear to undergo mutation in pituitary adenomas $(101,102)$.

Gadd45 $\gamma$. The normal human pituitary expresses GADD45 $\gamma$, a growth suppressor gene, while less than $10 \%$ of pituitary adenomas express the gene. Interestingly, transfected GADD45 $\gamma$ also reduces pituitary tumor cell proliferation in vitro (103).

Prolactin. PRL itself exhibits autocrine regulation of pituitary cell growth, and female mice in which the PRL gene is disrupted develop early pituitary hyperplasia, with definitive pituitary adenoma formation by 8 months (104). These tumors appear to arise from authentic lactotroph cells, albeit devoid of PRL, and may be secondary to deficient central dopaminergic tone in the absence of PRL.

Activating oncogenes and growth factors. Multiple growth factor and oncogene expression alterations have been described for pituitary tumors, and these changes may all contribute to the disordered intrapituitary growth milieu. Several reports have excluded involvement of oncogenes, including ras, $c-m y c, c-m y b$, and $c$-fos, in most pituitary tumors, although alterations are sometimes associated with local tumor invasiveness or aggression (78). Pituitary tumors do not commonly bear mutations of the ras gene family, and oncogenic mutations in codons 12, 13, and 61 were reported in highly invasive pituitary tumors, suggesting that ras activation is limited to pituitary tumor aggression or the rare metastatic occurrence (105). Although pituitary PPAR $\gamma$ expression is restricted to corticotroph cells, this receptor is abundantly expressed in most pituitary tumors (40). PPAR $\gamma$ ligands also block growth of experimental pituitary tumors (106). Galanin is induced by estrogen and stimulates lactotroph tumor proliferation, and mice with disrupted galanin expression exhibit lactotroph hypoplasia (107).

Chromosomal instability. About half of all pituitary tumors are grossly aneuploid (2), but the reported gain or loss of chromosomes is inconsistent (108). Chromosomal instability occurs as a result of disruption of cell cycle checkpoints, which control mitotic fidelity, resulting in chromosomal instability. These lesions may include mutation of genes responsible for (a) cell cycle regulation, (b) mitotic spindle assembly check- 


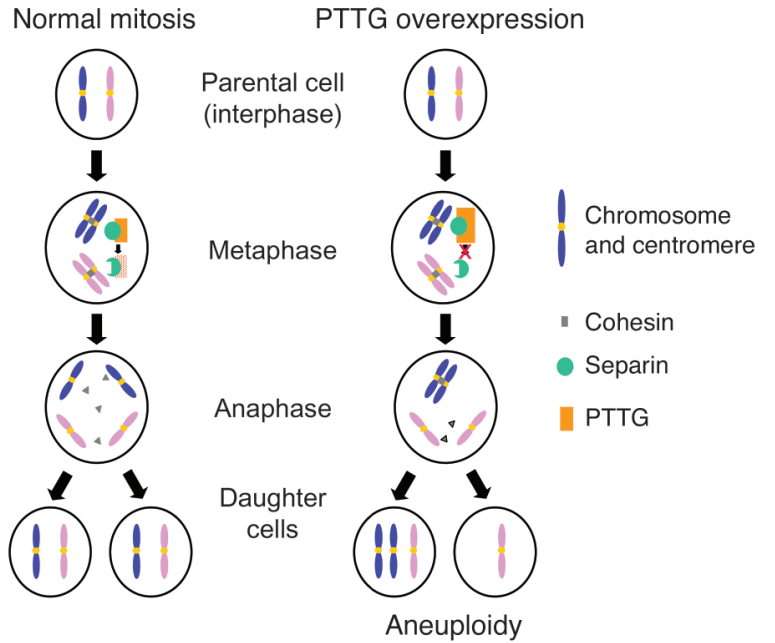

\section{Figure 6}

Securin function and aneuploidy. Normal mitosis (left): PTTG acts as a mammalian securin that maintains sister chromatid adherence during mitosis. Sister chromatids are bound with cohesions, and PTTG inactivates separin, an enzyme that regulates cohesin degradation. At the end of metaphase, securin degradation by an anaphase-promoting complex releases tonic separin inhibition, which in turn mediates cohesin degradation, thus releasing sister chromatids for equal separation into daughter cells. PTTG overexpression (right) may disrupt equal sister chromatid separation and result in aneuploidy. Adapted with permission from Brain Pathology (143).

point signaling, and (c) attachment of kinetochores to microtubules (109). Although not uniformly accepted (110), aneuploidy and chromosomal instability have been implicated as prerequisites for, rather than resulting from, tumor development.

Pttg was isolated by mRNA differential display of rat pituitary tumor cells and normal pituitary tissue (111). PTTG is expressed in selected normal tissues undergoing active cell turnover, including testis and lymphopoietic tissues, and is abundantly expressed in several tumor types, including pituitary, thyroid, colon, and breast $(37,112-115)$. PTTG is overexpressed in pituitary tumors, correlates with pituitary tumor invasiveness, behaves as a transactivator and a potent transforming gene (116), stimulates FGF2 production (117), and induces angiogenesis (118).

Stimulation of FGF by PTTG theoretically would suffice to explain PTTG tumorigenesis. It is not clear, though, which is the initiator, but increased expression of either PTTG or FGF- $\beta$ results in enhanced expression of the other. Although the positive autofeedback of $P T T G$ and FGF- $\beta$ suggests important roles in pituitary tumorigenesis, the role of vascularity (119) in pituitary tumorigenesis is controversial. Some investigators have observed increased pituitary adenoma vascularity, while others have reported fewer intratumoral vessels.

PTTG tumor overexpression is not associated with coding or promoter mutations, including homologous SP1, CCAAT, cell cycle-dependent element, and cell cycle homology region motifs. The human PTTG pro- moter also contains sites important for tissue-specific, cAMP-mediated, and estrogen-responsive regulation.

Point mutations of several key proline residues in the PTTG C terminus result in a dominant negative PTTG mutant defective in transforming activity, which suppresses PRL gene expression and inhibits growth of experimental rat pituitary adenomas (120).

Securin function of PTTG and aneuploidy. PTTG has been identified as a mammalian securin protein critical in mitosis (121). The process of cell cycle progression is controlled by cell cycle and checkpoint mediators ensuring genomic stability and faithful, diploid daughter cell production during mitosis. Cohesion of sister chromatids and their faithful segregation to ensure a normal daughter cell gene complement is a fundamental step whose disruption leads to chromosome instability and aneuploidy. A complex series of events ensures timely and equal separation of sister chromatids during mitosis, when sister chromatids are synchronously, equally, and irreversibly segregated to daughter cells. Cohesins bind sister chromatids, and are degraded by separins upon completion of metaphase (122). PTTG behaves as a vertebrate securin that binds to and inactivates separase during metaphase (123). Nonvertebrate securin proteins bind separin, and inhibit its function, thus preventing cohesin degradation. Securins share sequence homology for a destruction box, which targets the genes for cell cycle-dependent degradation. Separase activation occurs by phosphorylation or by PTTG degradation at the metaphase-anaphase transition (124).

During anaphase, sister chromatids are separated by separase, which cleaves chromosomal cohesin. Separase is inactivated by securin, which is degraded at the metaphase-anaphase transition by the anaphase-promoting complex (122). This complex behaves as an ubiquitin ligase, ensuring appropriate chromosome segregation. High CDK1 activity also prevents sister chromatid separation by inhibiting separase phosphorylation, even in the absence of binding of securin to separase (124). Dual inhibition of sister chromatid separation at metaphase may therefore control separase activation via two distinct mechanisms: First, cyclin B may be partially proteolysed to reduce CDK1 activity, and second, securin is destroyed. This may explain why securin-deficient human cells are indeed viable with relatively normal anaphase timing (123) and also why the $\mathrm{Pttg}^{-1-}$ mouse is viable (125). When separase cleavage sites in human cohesin are mutated (126), similar anaphase defects are observed, as when PTTG loss or overexpression attenuates separase activity (123). Several lines of evidence thus support the concept of the securin function of mammalian PTTG. Consistent with its role in regulating chromosome segregation, $P T T G$ mRNA and protein levels vary with the cell cycle, disappearing at the end of the G2/M phase, and PTTG is also phosphorylated by CDC2 at the serine residue (127). PTTG overexpression in human JEG-3 and MG63 cells causes a partial G2/M block, suggesting a pause in mitosis, and results in disturbed chromatid separa- 
tion and aneuploidy $(128,129)$. Paradoxically, PTTG also causes p53-dependent and p53-independent apoptosis (130). p53 also interacts with securin, and a recent report indicates p53 inhibition by securin (131). PTTG is downregulated by degradation, and observations in single live cells support the concept that PTTG has to be degraded for a faithful cell cycle to occur (Figure 5). Similar delayed mitosis is reported in cells expressing nondegradable securin (132).

In adult mice, Pttg is required for tissue self-renewal, as Pttg-disrupted mice are viable and fertile, but display testicular, splenic (125), and pituitary hypoplasia (133). $\mathrm{Pttg}^{-/}$male animals more than 7 months of age develop hyperglycemia, accompanied by hypoinsulinemia, low pancreatic $\beta$ cell mass, and decreased $\beta$ cell replication (134). Pttg is directly implicated in chromosome segregation, as abnormal nuclei, increased aneuploidy, and premature centromere division are evident in cultured fibroblasts derived from Pttg-disrupted mouse embryos. Pituitary-directed Pttg transgenic overexpression also results in pituitary focal hyperplasia (133). Thus, both Pttg excess, as observed in tumors, and Pttg loss, as exemplified in the $\mathrm{Pttg}^{-1}$ mouse, lead to cell cycle disruption and aneuploidy.

The mechanisms involved in the oncogenic function for PTTG are still obscure. Genetic instability could therefore underly the transforming and tumorigenic effects of PTTG overexpression as well as its association with tumor aggressiveness. Chromosomal instability of hyperplastic pituitary cells could provide a growth advantage for ultimate progression of tumor growth. In a recent report of genes associated with malignant cell behavior, PTTG was identified as one of nine genes comprising the "expression signature" for metastatic potential of solid tumors (135). Nevertheless, true pituitary malignancy is exceedingly rare.

PTTG thus functions as a securin that regulates chromosome separation (Figure 6), and aberrant PTTG expression leading to chromosome mis-segregation appears to be an early link in the multistep initiation and progression of pituitary tumors.

Clinical implications. Several clinical benefits are now apparent as a consequence of the unraveling of the nature of genetic changes associated with pituitary tumor formation. Ascertainment of carrier status for known pituitary-associated germline mutations (e.g., MEN1 and CNC) should precede the screening of families known to harbor such mutations. Screening protocols for the surveillance of patients identified as being at risk for tumor development should be initiated to more clearly delineate the onset of a pituitary tumor. These include serial pituitary MRI imaging and, if relevant, biochemical screening markers, such as measuring serum PRL (for prolactinoma) or IGF-I levels (for acromegaly). Ultimately, understanding the nature of the genetic lesion will contribute to therapeutic decision-making. For example, patients harboring MEN I-associated pituitary adenomas appear to have tumors that are more aggressive and are more resistant to treatment than spo- radic tumors (136). Molecular profiling of pituitary tumor specimens will allow rational approaches to the timing of and requirement for postoperative therapies (medical or irradiation), especially if clinical outcomes will be correlated with these profiles. The identification of structurally and functionally intact somatostatin receptor subtypes and $\mathrm{D} 2$ receptors has resulted in development of selective peptide analogs as effective new therapies for pituitary tumors (137). Finally, unraveling the mechanisms underlying disordered pituitary growth will allow development of subcellular therapies, as has been demonstrated experimentally for direct Rb gene therapy (138) and for targeted PTTG inactivation for experimental pituitary tumors (120).

Conclusions. Pituitary cells are highly differentiated and are committed very early to synthesize unique hormone products. Key regulators of pituitary lineage development may sustain mutations resulting in pituitary hormone deficiency and pituitary hypoplasia. Defects in genes that function early in development have pleiotropic effects and result in multiple hormone deficiencies associated with aberrant structural development, whereas defects in genes that act as differentiating factors after lineage specification are associated with selective hormone-deficiency phenotypes. Early changes leading to pituitary tumorigenesis involve both intrinsic pituicyte alterations and altered availability of paracrine or endocrine regulatory factors regulating both hormone secretion and cell growth (Figure 6). Familial syndromes are associated with at least three genes that predispose to pituitary hyperplasia and tumorigenesis. Factors resulting in pituitary hyperplasia, including hypothalamic hormones, estrogens, and growth factors, likely facilitate a permissive intrapituitary milieu, potentiating genetic instability, cell mutation, and subsequent monoclonal growth expansion.

\section{Acknowledgments}

Work in the author's laboratory is supported by NIH grants CA75979 and DK64169.

1. Taniguchi, Y., Yasutaka, S., Kominami, R., and Shinohara, H. 2002. Proliferation and differentiation of rat anterior pituitary cells. Anat. Embryol. (Berl.). 206:1-11.

2. Levy, A., and Lightman, S. 2003. Molecular defects in the pathogenesis of pituitary tumours. Front. Neuroendocrinol. 24:94-127.

3. Asa, S.L., and Ezzat, S. 1998. The cytogenesis and pathogenesis of pituitary adenomas. Endocr. Rev. 19:798-827.

4. Faglia, G., and Spada, A. 2001. Genesis of pituitary adenomas: state of the art. J. Neurooncol. 54:95-110.

5. Prezant, T.R., and Melmed, S. 2002. Molecular pathogenesis of pituitary disorders. Current Opinion in Endocrinology \& Diabetes. 9:61-78.

6. Jeffcoate, W.J., Pound, N., Sturrock, N.D., and Lambourne, J. 1996. Longterm follow-up of patients with hyperprolactinaemia. Clin. Endocrinol. (Oxf.). 45:299-303.

7. Olson, L.E., and Rosenfeld, M.G. 2002. Perspective: genetic and genomic approaches in elucidating mechanisms of pituitary development. Endocrinology. 143:2007-2011.

8. Semina, E.V., et al. 1996. Cloning and characterization of a novel bicoidrelated homeobox transcription factor gene, RIEG, involved in Rieger syndrome. Nat. Genet. 14:392-399.

9. Netchine, I., et al. 2000. Mutations in LHX3 result in a new syndrome revealed by combined pituitary hormone deficiency. Nat. Genet. 25:182-186.

10. Machinis, K., et al. 2001. Syndromic short stature in patients with a germline mutation in the $\lim$ homeobox $\mathrm{lhx} 4$. Am. J. Hum. Genet. 69:961-968. 
11. Dattani, M.T., et al. 1998. Mutations in the homeobox gene HESX1/Hesx1 associated with septo-optic dysplasia in human and mouse. Nat. Genet. 19:125-133.

12. Liu, J., et al. 2001. Tbx19, a tissue-selective regulator of POMC gene expression. Proc. Natl. Acad. Sci. U. S. A. 98:8674-8679.

13. Lamolet, B., et al. 2001. A pituitary cell-restricted T box factor, Tpit, activates POMC transcription in cooperation with Pitx homeoproteins. Cell. 104:849-859.

14. Pulichino, A.M., et al. 2003. Tpit determines alternate fates during pituitary cell differentiation. Genes Dev. 17:738-747.

15. Cohen, L.E., and Radovick, S. 2002. Molecular basis of combined pituitary hormone deficiencies. Endocr. Rev. 23:431-442.

16. Sornson, M.W., et al. 1996. Pituitary lineage determination by the Prophet of Pit-1 homeodomain factor defective in Ames dwarfism. Nature. 384:327-333.

17. Li, S., et al. 1990. Dwarf locus mutants lacking three pituitary cell types result from mutations in the POU-domain gene pit-1. Nature. 347:528-533.

18. Cushman, L.J., et al. 2001. Persistent Prop1 expression delays gonadotrope differentiation and enhances pituitary tumor susceptibility. Hum. Mol. Genet. 10:1141-1153.

19. Riepe, F.G., et al. 2001. Longitudinal imaging reveals pituitary enlargement preceding hypoplasia in two brothers with combined pituitary hormone deficiency attributable to PROP1 mutation. J. Clin. Endocrinol. Metab. 86:4353-4357.

20. Osorio, M.G., et al. 2002. Pituitary magnetic resonance imaging and function in patients with growth hormone deficiency with and without mutations in GHRH-R, GH-1, or PROP-1 genes. J. Clin. Endocrinol. Metab. 87:5076-5084.

21. Teinturier, C., et al. 2002. Pseudotumor of the pituitary due to PROP-1 deletion. J. Pediatr. Endocrinol. Metab. 15:95-101.

22. Pellegrini, I., et al. 1994. Pit-1 gene expression in the human pituitary and pituitary adenomas. J. Clin. Endocrinol. Metab. 79:189-196.

23. Nakamura, S., et al. 1999. Prop-1 gene expression in human pituitary tumors. J. Clin. Endocrinol. Metab. 84:2581-2584.

24. Moons, D.S., et al. 2002. Pituitary hypoplasia and lactotroph dysfunction in mice deficient for cyclin-dependent kinase-4. Endocrinology. 143:3001-3008.

25. Horvath, E., Kovacs, K., and Scheithauer, B.W. 1999. Pituitary hyperplasia. Pituitary. 1:169-179.

26. Chanson, P., et al. 2001. Normal pituitary hypertrophy as a frequent cause of pituitary incidentaloma: a follow-up study. J. Clin. Endocrinol. Metab. 86:3009-3015.

27. Scheithauer, B.W., et al. 1990. The pituitary gland in pregnancy: a clinicopathologic and immunohistochemical study of 69 cases. Mayo Clin. Proc. 65:461-474.

28. Coogan, P.F., Baron, J.A., and Lambe, M. 1995. Parity and pituitary adenoma risk. J. Natl. Cancer Inst. 87:1410-1411.

29. Severinghaus, A.E. 1937. Cellular changes in the anterior hypophysis with special references to its secretory activities. Physiol. Rev. 17:556-566.

30. Vidal, S., Horvath, E., Kovacs, K., Lloyd, R.V., and Smyth, H.S. 2001. Reversible transdifferentiation: interconversion of somatotrophs and lactotrophs in pituitary hyperplasia. Mod. Pathol. 14:20-28.

31. Childs, G.V. 2002. Development of gonadotropes may involve cyclic transdifferentiation of growth hormone cells. Arch. Physiol. Biochem. 110:42-49.

32. Ivarie, R., and Morris, J. 1983. Phenotypic switching in GH3 rat pituitary tumor cells: linked expression of growth hormone and another hormonally responsive protein. DNA. 2:113-120.

33. Vidal, S., et al. 2000. Transdifferentiation of somatotrophs to thyrotrophs in the pituitary of patients with protracted primary hypothyroidism. Virchows Arch. 436:43-51.

34. Bevan, J.S., et al. 2002. Primary medical therapy for acromegaly: an open, prospective, multicenter study of the effects of subcutaneous and intramuscular slow-release octreotide on growth hormone, insulin-like growth factor-I, and tumor size. J. Clin. Endocrinol. Metab. 87:4554-4563.

35. Corsello, S.M., et al. 2003. Giant prolactinomas in men: efficacy of cabergoline treatment. Clin. Endocrinol. (Oxf.). 58:662-670.

36. Shupnik, M.A., et al. 1998. Selective expression of estrogen receptor alpha and beta isoforms in human pituitary tumors. J. Clin. Endocrinol. Metab. 83:3965-3972.

37. Heaney, A.P., Horwitz, G.A., Wang, Z., Singson, R., and Melmed, S. 1999. Early involvement of estrogen-induced pituitary tumor transforming gene and fibroblast growth factor expression in prolactinoma pathogenesis. Nat. Med. 5:1317-1321.

38. Walker, B.E., and Kurth, L.A. 1993. Pituitary tumors in mice exposed prenatally to diethylstilbestrol. Cancer Res. 53:1546-1549.

39. Chaidarun, S.S., Swearingen, B., and Alexander, J.M. 1998. Differential expression of estrogen receptor- $\beta$ (ER $\beta$ ) in human pituitary tumors: functional interactions with $\mathrm{ER} \alpha$ and a tumor-specific splice variant. J. Clin. Endocrinol. Metab. 83:3308-3315.

40. Heaney, A.P., Fernando, M., and Melmed, S. 2002. Functional role of estrogen in pituitary tumor pathogenesis. J. Clin. Invest. 109:277-283. doi:10.1172/JCI200214264

41. Heaney, A.P., Fernando, M., Yong, W.H., and Melmed, S. 2002. Functional PPAR- $\gamma$ receptor is a novel therapeutic target for ACTH-secreting pituitary adenomas. Nat. Med. 8:1281-1287.

42. Kovacs, K., Stefaneanu, L., Ezzat, S., and Smyth, H.S. 1994. Prolactin-producing pituitary adenoma in a male-to-female transsexual patient with protracted estrogen administration. A morphologic study. Arch. Pathol. Lab. Med. 118:562-565.

43. Vidal, S., et al. 2002. Prolactin-producing pituitary adenoma associated with prolactin cell hyperplasia. Endocr. Pathol. 13:157-165.

44. Muglia, L.J., Bethin, K.E., Jacobson, L., Vogt, S.K., and Majzoub, J.A. 2000. Pituitary-adrenal axis regulation in CRH-deficient mice. Endocr. Res. 26:1057-1066.

45. Mayo, K.E., et al. 1988. Dramatic pituitary hyperplasia in transgenic mice expressing a human growth hormone-releasing factor gene. Mol. Endocrinol. 2:606-612.

46. Asa, S.L., et al. 1992. Pituitary adenomas in mice transgenic for growth hormone-releasing hormone. Endocrinology. 131:2083-2089.

47. Asa, S.L., Kelly, M.A., Grandy, D.K., and Low, M.J. 1999. Pituitary lactotroph adenomas develop after prolonged lactotroph hyperplasia in dopamine D2 receptor-deficient mice. Endocrinology. 140:5348-5355.

48. Carey, R.M., et al. 1984. Ectopic secretion of corticotropin-releasing factor as a cause of Cushing's syndrome. A clinical, morphologic, and biochemical study. N. Engl. J. Med. 311:13-20.

49. Sano, T., Asa, S.L., and Kovacs, K. 1988. Growth hormone-releasing hormone-producing tumors: clinical, biochemical, and morphological manifestations. Endocr. Rev. 9:357-373.

50. Thorner, M.O., et al. 1982. Somatotroph hyperplasia. Successful treatment of acromegaly by removal of a pancreatic islet tumor secreting a growth hormone-releasing factor. J. Clin. Invest. 70:965-977.

51. Schuff, K.G., et al. 2002. Lack of prolactin receptor signaling in mice results in lactotroph proliferation and prolactinomas by dopaminedependent and -independent mechanisms. J. Clin. Invest. 110:973-981. doi:10.1172/JCI200215912.

52. Friedman, E., et al. 1994. Normal structural dopamine type 2 receptor gene in prolactin-secreting and other pituitary tumors. J. Clin. Endocrinol. Metab. 78:568-574.

53. Petersenn, S., Heyens, M., Ludecke, D.K., Beil, F.U., and Schulte, H.M. 2000. Absence of somatostatin receptor type 2 A mutations and gip oncogene in pituitary somatotroph adenomas. Clin. Endocrinol. (Oxf) 52:35-42

54. Ballare, E., et al. 2001. Mutation of somatostatin receptor type 5 in an acromegalic patient resistant to somatostatin analog treatment. J. Clin. Endocrinol. Metab. 86:3809-3814.

55. Ando, S., Sarlis, N.J., Oldfield, E.H., and Yen, P.M. 2001. Somatic mutation of TR $\beta$ can cause a defect in negative regulation of TSH in a TSHsecreting pituitary tumor. J. Clin. Endocrinol. Metab. 86:5572-5576.

56. Chanson, P., et al. 1998. Absence of activating mutations in the GnRH receptor gene in human pituitary gonadotroph adenomas. Eur. J. Endocrinol. 139:157-160.

57. Faccenda, E., Melmed, S., Bevan, J.S., and Eidne, K.A. 1996. Structure of the thyrotrophin-releasing hormone receptor in human pituitary adenomas. Clin. Endocrinol. (Oxf.). 44:341-347.

58. Lee, E.J., et al. 2001. Absence of constitutively activating mutations in the GHRH receptor in GH-producing pituitary tumors. J. Clin. Endocrinol. Metab. 86:3989-3995.

59. Barinaga, M., Bilezikjian, L.M., Vale, W.W., Rosenfeld, M.G., and Evans, R.M. 1985. Independent effects of growth hormone releasing factor on growth hormone release and gene transcription. Nature. 314:279-281.

60. Billestrup, N., Swanson, L.W., and Vale, W. 1986. Growth hormonereleasing factor stimulates proliferation of somatotrophs in vitro. Proc. Natl. Acad. Sci. U. S. A. 83:6854-6857.

61. Lin, S.C., et al. 1993. Molecular basis of the little mouse phenotype and implications for cell type-specific growth. Nature. 364:208-213.

62. Salvatori, R., et al. 2001. Absence of mutations in the growth hormone $(\mathrm{GH})$-releasing hormone receptor gene in $\mathrm{GH}$-secreting pituitary adenomas. Clin. Endocrinol. (Oxf). 54:301-307.

63. Weinstein, L.S., et al. 1991. Activating mutations of the stimulatory G protein in the McCune-Albright syndrome. N. Engl. J. Med. 325:1688-1695.

64. Vallar, L., Spada, A., and Giannattasio, G. 1987. Altered Gs and adenylate cyclase activity in human GH-secreting pituitary adenomas. Nature. 330:566-568.

65. Bertherat, J., Chanson, P., and Montminy, M. 1995. The cyclic adenosine $3^{\prime}, 5^{\prime}$-monophosphate-responsive factor CREB is constitutively activated in human somatotroph adenomas. Mol. Endocrinol. 9:777-783.

66. Struthers, R.S., Vale, W.W., Arias, C., Sawchenko, P.E., and Montminy, M.R. 1991. Somatotroph hypoplasia and dwarfism in transgenic mice expressing a non-phosphorylatable CREB mutant. Nature. 350:622-624.

67. Lania, A., et al. 1998. Constitutively active Gs $\alpha$ is associated with an increased phosphodiesterase activity in human growth hormone-secreting adenomas. J. Clin. Endocrinol. Metab. 83:1624-1628. 
68. Kirschner, L.S., et al. 2000. Mutations of the gene encoding the protein kinase A type I- $\alpha$ regulatory subunit in patients with the Carney complex. Nat. Genet. 26:89-92.

69. Stratakis, C.A., et al. 1996. Cytogenetic and microsatellite alterations in tumors from patients with the syndrome of myxomas, spotty skin pigmentation, and endocrine overactivity (Carney complex). J. Clin. Endocrinol. Metab. 81:3607-3614.

70. Casey, M., et al. 2000. Mutations in the protein kinase A R $1 \alpha$ regulatory subunit cause familial cardiac myxomas and Carney complex. J. Clin. Invest. 106: R31-38.

71. Gonsky, R., Herman, V., Melmed, S., and Fagin, J. 1991. Transforming DNA sequences present in human prolactin-secreting pituitary tumors. Mol. Endocrinol. 5:1687-1695.

72. Shimon, I., Huttner, A., Said, J., Spirina, O.M., and Melmed, S. 1996 Heparin-binding secretory transforming gene (hst) facilitates rat lactotrope cell tumorigenesis and induces prolactin gene transcription. J. Clin. Invest. 97:187-195.

73. Shimon, I., Hinton, D.R., Weiss, M.H., and Melmed, S. 1998. Prolactinomas express human heparin-binding secretory transforming gene (hst) protein product: marker of tumour invasiveness. Clin. Endocrinol. (Oxf). 48:23-29.

74. Ezzat, S., Zheng, L., Zhu, X.-F., Wu, G.E., and Asa, S.L. 2002. Targeted expression of a human pituitary tumor-derived isoform of FGF receptor-4 recapitulates pituitary tumorigenesis. J. Clin. Invest. 109:69-78. doi:10.1172/JCI200214306.

75. McAndrew, J., Paterson, A.J., Asa, S.L., McCarthy, K.J., and Kudlow, J.E. 1995. Targeting of transforming growth factor- $\alpha$ expression to pituitary lactotrophs in transgenic mice results in selective lactotroph proliferation and adenomas. Endocrinology. 136:4479-4488.

76. Paez-Pereda, M., et al. 2003. Involvement of bone morphogenetic protein 4 (BMP-4) in pituitary prolactinoma pathogenesis through a Smad/estrogen receptor crosstalk. Proc. Natl. Acad. Sci. U. S. A. 100:1034-1039.

77. Borrelli, E., Sawchenko, P.E., and Evans, R.M. 1992. Pituitary hyperplasia induced by ectopic expression of nerve growth factor. Proc. Natl. Acad. Sci. U. S. A. 89:2764-2768

78. Woloschak, M., Roberts, J.L., and Post, K. 1994. c-myc, c-fos, and c-myb gene expression in human pituitary adenomas. J. Clin. Endocrinol. Metab. 79:253-257.

79. Herman, V., Fagin, J., Gonsky, R., Kovacs, K., and Melmed, S. 1990. Clonal origin of pituitary adenomas. J. Clin. Endocrinol. Metab. 71:1427-1433.

80. Alexander, J.M., et al. 1990. Clinically nonfunctioning pituitary tumors are monoclonal in origin. J. Clin. Invest. 86:336-340.

81. Berezin, M., and Karasik, A. 1995. Familial prolactinoma. Clin. Endocrinol. (Oxf). 42:483-486.

82. Tanaka, C., et al. 1998. Absence of germ-line mutations of the multiple endocrine neoplasia type 1 (MEN1) gene in familial pituitary adenoma in contrast to MEN1 in Japanese. J. Clin. Endocrinol. Metab. 83:960-965.

83. Gadelha, M.R., et al. 2000. Isolated familial somatotropinomas: establishment of linkage to chromosome 11q13.1-11q13.3 and evidence for a potential second locus at chromosome 2p16-12. J. Clin. Endocrinol. Metab. 85:707-714.

84. Simpson, D.J., et al. 2003. Genome-wide amplification and allelotyping of sporadic pituitary adenomas identify novel regions of genetic loss. Genes Chromosomes Cancer. 37:225-236.

85. Bates, A.S., et al. 1997. Allelic deletion in pituitary adenomas reflects aggressive biological activity and has potential value as a prognostic marker. J. Clin. Endocrinol. Metab. 82:818-824.

86. Crabtree, J.S., et al. 2001. A mouse model of multiple endocrine neoplasia, type 1, develops multiple endocrine tumors. Proc. Natl. Acad. Sci. U. S. A. 98:1118-1123.

87. Zhuang, Z., et al. 1997. Mutations of the MEN1 tumor suppressor gene in pituitary tumors. Cancer Res. 57:5446-5451.

88. Chau, B.N., and Wang, J.Y. 2003. Coordinated regulation of life and death by RB. Nat. Rev. Cancer. 3:130--138.

89. Jacks, T., et al. 1992. Effects of an Rb mutation in the mouse. Nature 359:295-300.

90. Zhu, J., et al. 1994. Human pituitary adenomas show no loss of heterozygosity at the retinoblastoma gene locus. J. Clin. Endocrinol. Metab. 78:922-927.

91. Woloschak, M., Roberts, J.L., and Post, K.D. 1994. Loss of heterozygosity at the retinoblastoma locus in human pituitary tumors. Cancer. 74:693-696

92. Woloschak, M., Yu, A., Xiao, J., and Post, K.D. 1996. Abundance and state of phosphorylation of the retinoblastoma gene product in human pituitary tumors. Int. J. Cancer. 67:16-19.

93. Kiyokawa, H., et al. 1996. Enhanced growth of mice lacking the cyclindependent kinase inhibitor function of $\mathrm{p} 27^{\mathrm{Kip}}{ }^{1}$. Cell. 85:721-732.

94. Lidhar, K., et al. 1999. Low expression of the cell cycle inhibitor p27Kip1 in normal corticotroph cells, corticotroph tumors, and malignant pituitary tumors. J. Clin. Endocrinol. Metab. 84:3823-3830.

95. Shirane, M., et al. 1999. Down-regulation of $\mathrm{p}^{27^{\mathrm{Kip} 1}}$ by two mecha- nisms, ubiquitin-mediated degradation and proteolytic processing J. Biol. Chem. 274:13886-13893.

96. Carneiro, C., et al. 2003. p27 deficiency desensitizes $\mathrm{Rb}^{-/-}$cells to signals that trigger apoptosis during pituitary tumor development. Oncogene. 22:361-369.

97. Riss, D., et al. 2003. Differential expression of galectin-3 in pituitary tumors. Cancer Res. 63:2251-2255.

98. Fero, M.L., et al. 1996. A syndrome of multiorgan hyperplasia with features of gigantism, tumorigenesis, and female sterility in p27 ${ }^{\mathrm{Kip}}{ }^{1}$-deficient mice. Cell. 85:733-744.

99. Franklin, D.S., et al. 1998. CDK inhibitors $\mathrm{p} 18^{\mathrm{INK} 4 \mathrm{c}}$ and $\mathrm{p} 27^{\mathrm{Kip} 1}$ mediate two separate pathways to collaboratively suppress pituitary tumorigenesis. Genes Dev. 12:2899-2911.

100.Frost, S.J., Simpson, D.J., Clayton, R.N., and Farrell, W.E. 1999. Transfection of an inducible p16/CDKN2A construct mediates reversible growth inhibition and G1 arrest in the AtT20 pituitary tumor cell line. Mol. Endocrinol. 13:1801-1810.

101.Thapar, K., Scheithauer, B.W., Kovacs, K., Pernicone, P.J., and Laws, E.R., Jr. 1996. p53 expression in pituitary adenomas and carcinomas: correlation with invasiveness and tumor growth fractions. Neurosurgery. 38:763-770; discussion 770-771

102.Levy, A., Hall, L., Yeudall, W.A., and Lightman, S.L. 1994. p53 gene mutations in pituitary adenomas: rare events. Clin. Endocrinol. (Oxf). 41:809-814.

103.Zhang, X., et al. 2002. Loss of expression of GADD45 $\gamma$, a growth inhibitory gene, in human pituitary adenomas: implications for tumorigenesis. J. Clin. Endocrinol. Metab. 87:1262-1267.

104.Cruz-Soto, M.E., Scheiber, M.D., Gregerson, K.A., Boivin, G.P., and Horseman, N.D. 2002. Pituitary tumorigenesis in prolactin gene-disrupted mice. Endocrinology. 143:4429-4436.

105.Pei, L., Melmed, S., Scheithauer, B., Kovacs, K., and Prager, D. 1994. $\mathrm{H}$-ras mutations in human pituitary carcinoma metastases. J. Clin. Endocrinol. Metab. 78:842-846.

106. Heaney, A.P., Fernando, M., and Melmed, S. 2003. PPAR- $\gamma$ receptor lig ands: novel therapy for pituitary adenomas. J. Clin. Invest. 111:1381-1388. doi:10.1172/JCI200316575.

107. Wynick, D., et al. 1998. Galanin regulates prolactin release and lactotroph proliferation. Proc. Natl. Acad. Sci. U. S. A. 95:12671-12676.

108.Hui, A.B., Pang, J.C., Ko, C.W., and Ng, H.K. 1999. Detection of chromosomal imbalances in growth hormone-secreting pituitary tumors by comparative genomic hybridization. Hum. Pathol. 30:1019-1023.

109.Lengauer, C., Kinzler, K.W., and Vogelstein, B. 1998. Genetic instabilities in human cancers. Nature. 396:643-649.

110.Zimonjic, D., Brooks, M.W., Popescu, N., Weinberg, R.A., and Hahn, W.C 2001. Derivation of human tumor cells in vitro without widespread genomic instability. Cancer Res. 61:8838-8844.

111.Pei, L., and Melmed, S. 1997. Isolation and characterization of a pituitary tumor-transforming gene (PTTG). Mol. Endocrinol. 11:433-441.

112. Heaney, A.P., et al. 2000. Expression of pituitary-tumour transforming gene in colorectal tumours. Lancet. 355:716-719.

113.Saez, C., et al. 1999. hpttg is over-expressed in pituitary adenomas and other primary epithelial neoplasias. Oncogene. 18:5473-5476.

114.Zhang, X., et al. 1999. Pituitary tumor transforming gene (PTTG) expression in pituitary adenomas. J. Clin. Endocrinol. Metab. 84:761-767.

115.Zhang, X., et al. 1999. Structure, expression, and function of human pituitary tumor-transforming gene (PTTG). Mol. Endocrinol. 13:156-166.

116.Pei, L. 2000. Activation of mitogen-activated protein kinase cascade regulates pituitary tumor-transforming gene transactivation function. J. Biol. Chem. 275:31191-31198.

117. McCabe, C.J., et al. 2003. Expression of pituitary tumour transforming gene (PTTG) and fibroblast growth factor-2 (FGF-2) in human pituitary adenomas: relationships to clinical tumour behaviour. Clin. Endocrinol. (Oxf.). 58:141-150

118.McCabe, C.J., et al. 2002. Vascular endothelial growth factor, its receptor KDR/Flk-1, and pituitary tumor transforming gene in pituitary tumors. J. Clin. Endocrinol. Metab. 87:4238-4244.

119. Turner, H.E., et al. 2000. Angiogenesis in pituitary adenomas - relationship to endocrine function, treatment and outcome. J. Endocrinol. 165:475-481.

120.Horwitz, G.A., Miklovsky, I., Heaney, A.P., Ren, S.G., and Melmed, S 2003. Human pituitary tumor-transforming gene (PTTG1) motif suppresses prolactin expression. Mol. Endocrinol. 17:600-609.

121.Zou, H., McGarry, T.J., Bernal, T., and Kirschner, M.W. 1999. Identification of a vertebrate sister-chromatid separation inhibitor involved in transformation and tumorigenesis. Science. 285:418-422.

122. Nasmyth, K. 2002. Segregating sister genomes: the molecular biology of chromosome separation. Science. 297:559-565.

123.Jallepalli, P.V., et al. 2001. Securin is required for chromosomal stability in human cells. Cell. 105:445-457.

124.Stemmann, O., Zou, H., Gerber, S.A., Gygi, S.P., and Kirschner, M.W. 2001. Dual inhibition of sister chromatid separation at metaphase. Cell. 107:715-726. 
125.Wang, Z., Yu, R., and Melmed, S. 2001. Mice lacking pituitary tumor transforming gene show testicular and splenic hypoplasia, thymic hyperplasia, thrombocytopenia, aberrant cell cycle progression, and premature centromere division. Mol. Endocrinol. 15:1870-1879.

126. Hauf, S., Waizenegger, I.C., and Peters, J.M. 2001. Cohesin cleavage by separase required for anaphase and cytokinesis in human cells. Science. 293:1320-1323.

127. Ramos-Morales, F., et al. 2000. Cell cycle regulated expression and phosphorylation of hpttg proto- oncogene product. Oncogene. 19:403-409.

128.Yu, R., Ren, S.G., Horwitz, G.A., Wang, Z., and Melmed, S. 2000. Pituitary tumor transforming gene (PTTG) regulates placental JEG-3 cell division and survival: evidence from live cell imaging. Mol. Endocrinol. 14:1137-1146.

129.Yu, R., Lu, W., and Melmed, S. 2003. Overexpressed pituitary tumor transforming gene (PTTG) causes aneuploidy in live human cells. Endocrinology. 144:4991-4998.

130.Yu, R., Heaney, A.P., Lu, W., Chen, J., and Melmed, S. 2000. Pituitary tumor transforming gene causes aneuploidy and p53-dependent and p53-independent apoptosis. J. Biol. Chem. 275:36502-36505.

131. Bernal, J.A., et al. 2002. Human securin interacts with p53 and modulates p53-mediated transcriptional activity and apoptosis. Nat. Genet. 32:306-311.

132.Zur, A., and Brandeis, M. 2001. Securin degradation is mediated by fzy and fzr, and is required for complete chromatid separation but not for cytokinesis. Embo J. 20:792-801.

133.Abbud, R., et al. 2003. Molecular pathogenesis. In 8th International Pitu itary Congress. Pituitary Society, New York, New York, USA. (Abstr. S1)

134.Wang, Z., Moro, E., Kovacs, K., Yu, R., and Melmed, S. 2003. Pituitary tumor transforming gene-null male mice exhibit impaired pancreatic beta cell proliferation and diabetes. Proc. Natl. Acad. Sci. U. S. A. 100:3428-3432.

135. Ramaswamy, S., Ross, K.N., Lander, E.S., and Golub, T.R. 2003. A molecular signature of metastasis in primary solid tumors. Nat. Genet. 33:49-54.

136.Verges, B., et al. 2002. Pituitary disease in MEN type 1 (MEN1): data from the France-Belgium MEN1 multicenter study. J. Clin. Endocrinol. Metab. 87:457-465.

137. Shimon, I., et al. 1997. Somatostatin receptor (SSTR) subtype-selective analogues differentially suppress in vitro growth hormone and prolactin in human pituitary adenomas. Novel potential therapy for functional pituitary tumors. J. Clin. Invest. 100:2386-2392.

138. Riley, D.J., Nikitin, A.Y., and Lee, W.H. 1996. Adenovirus-mediated retinoblastoma gene therapy suppresses spontaneous pituitary melanotroph tumors in $\mathrm{Rb}+$ - mice. Nat. Med. 2:1316-1321.

139. Melmed, S., and Kleinberg, D.L. 2003. Anterior pituitary. In Williams text book of endocrinology. P. Larsen, H.M. Kronenberg, S. Melmed, and K.S. Polonsky, editors. W.B. Saunders. Philadelphia, Pennsylvania, USA. 177-279.

140.Shimon, I., and Melmed, S. 1997. Anterior pituitary hormones. In Endocrinology: basic and clinical principles. P.M. Conn, and S. Melmed, editors. Humana Press. Totowa, New Jersey, USA. 211-222.

141.Amselem, S. 2001. Perspectives on the molecular basis of developmenta defects in the human pituitary region. In Hypothalamic-pituitary development: genetic and clinical aspects. R. Rappaport, and S. Amselem, editors. S. Karger Publishing. Basel, Switzerland. 30-47.

142.Schmitt, C.A. 2003. Senescence, apoptosis and therapy-cutting the lifelines of cancer. Nat. Rev. Cancer. 3:286-295.

143.Yu, R., and Melmed, S. 2001. Oncogene activation in pituitary tumors. Brain Pathology. 11:328-341.

144. Clayton, R.N. 1999. Sporadic pituitary tumors: from epidemiology to use of databases. Baillieres Best Pract. Res. Clin. Endocrinol. Metab. 13:451-460.

145.Kovacs, K., and Horvath, E. 1986. Pathology of growth hormone-producing tumors of the human pituitary. Semin. Diagn. Pathol. 3:18-33.

146.Scheithauer, B.W., Horvath, E., Lloyd, R.V., and Kovacs, K. 1994. Pathology of pituitary adenomas and pituitary hyperplasia. In Diagnosis and management of pituitary tumors. K. Thapar, K. Kovacs, B. Scheitnauer, and R. Lloyd, editors. Humana Press Inc. Totowa, New Jersey, USA. 91-154.

147.Minderman, T., and Wilson, C.B. 1994. Age-related and gender-related occurrence of pituitary adenomas. Clin. Endocrinol. (Oxf). 41:359-364.

148.Asa, S.L., Horvath, E., and Kovacs, K. 1993. Pituitary neoplasms: an overview of the clinical presentation, diagnosis, treatment and pathology. In Endocrine tumours. E.L. Mazzaferri and N.A. Samaan, editors. Blackwell Scientific Publications. Boston, Massachusetts, USA. 77-112.

149. Prezant, T., and Melmed, S. 1998. Pituitary oncogenes. In Pituitary tumours: epidemiology, pathogenesis and management. S.M. Webb, editor. Bioscientifica. Bristol, United Kingdom. 81-93. 